NBER WORKING PAPER SERIES

\title{
PRESCRIPTION DRUG ADVERTISING AND DRUG UTILIZATION: THE ROLE OF MEDICARE PART D
}

\author{
Abby Alpert \\ Darius Lakdawalla \\ Neeraj Sood \\ Working Paper 21714 \\ http://www.nber.org/papers/w21714 \\ NATIONAL BUREAU OF ECONOMIC RESEARCH \\ 1050 Massachusetts Avenue \\ Cambridge, MA 02138 \\ November 2015
}

We are grateful for helpful comments from Marianne Bitler, Tina Marsh Dalton, Josh Gottlieb, Eric Helland, Mireille Jacobson, Sean Nicholson, David Powell, Brad Shapiro, Kosali Simon, and seminar and conference participants at the Conference of the American Society of Health Economists, Annual Health Economics Conference, Midwest Health Economics Conference, NBER Summer Institute Health Care Meeting, Southern California Conference in Applied Microeconomics, University of California-Irvine, and University of Southern California. We thank Laura Gascue, Karina Hermawan, and Chia-Wei Lin for excellent research assistance and programming. This research was supported by the National Institute on Aging P01 AG033559. All errors are our own. The views expressed herein are those of the authors and do not necessarily reflect the views of the National Bureau of Economic Research.

At least one co-author has disclosed a financial relationship of potential relevance for this research. Further information is available online at http://www.nber.org/papers/w21714.ack

NBER working papers are circulated for discussion and comment purposes. They have not been peerreviewed or been subject to the review by the NBER Board of Directors that accompanies official NBER publications.

(C) 2015 by Abby Alpert, Darius Lakdawalla, and Neeraj Sood. All rights reserved. Short sections of text, not to exceed two paragraphs, may be quoted without explicit permission provided that full credit, including $(\subset$ notice, is given to the source. 
Prescription Drug Advertising and Drug Utilization: The Role of Medicare Part D Abby Alpert, Darius Lakdawalla, and Neeraj Sood

NBER Working Paper No. 21714

November 2015

JEL No. H51,I10,I18

\begin{abstract}
$\underline{\text { ABSTRACT }}$
Pharmaceutical firms currently spend over \$4 billion on direct-to-consumer advertising (DTCA) of prescription drugs, a nearly 30 -fold increase since 1993 that has led to much debate about its value to patients. We examine how DTCA influences drug utilization along the extensive and intensive margins by exploiting a large and plausibly exogenous shock to DTCA driven by the introduction of Medicare Part D in 2006. Using data on advertising for local media markets from Nielsen, we show that Part $\mathrm{D}$ led to large relative increases in DTCA in geographic areas with a high concentration of Medicare beneficiaries compared to areas with a low concentration. We examine the effects of this sudden differential increase in advertising on non-elderly individuals to isolate the effects of advertising on drug utilization from the direct effects of Part D. Using data from pharmacy claims, we find substantial differential increases in drug utilization that mirror the increases in DTCA after Part D. These effects are driven both by increased take-up of treatment and improved drug adherence. Our results imply significant spillovers from Medicare Part D onto the under-65 population and an important role for non-price factors in influencing prescription drug utilization.
\end{abstract}

\author{
Abby Alpert \\ Paul Merage School of Business \\ University of California, Irvine \\ Irvine, CA 92697-3125 \\ aealpert@uci.edu \\ Darius Lakdawalla \\ Schaeffer Center for Health Policy \\ and Economics \\ University of Southern California \\ 3335 S. Figueroa St, Unit A \\ Los Angeles, CA 90089-7273 \\ and NBER \\ dlakdawa@healthpolicy.usc.edu
}

\author{
Neeraj Sood \\ Schaeffer Center for Health Policy \\ and Economics \\ University of Southern California \\ 3335 S. Figueroa Street, Unit A \\ Los Angeles, CA 90089-7273 \\ and NBER \\ nsood@healthpolicy.usc.edu
}




\section{Introduction}

Spending on direct-to-consumer advertising (DTCA) of prescription drugs in the U.S. has increased dramatically in the last two decades from \$150 million in 1993 to over $\$ 4$ billion in 2010 (Dave, 2013; Dave and Saffer, 2012). This rise was precipitated by a 1997 FDA policy change that relaxed restrictions on drug advertising. ${ }^{1}$ Most drug advertising occurs on television, where pharmaceuticals represented the third highest category of advertising expenditures in 2014 (behind automotive and fast food restaurant advertising). ${ }^{2}$ Nielsen estimates that an average of 80 pharmaceutical ads air every hour on American television. ${ }^{3}$ Given that adults ages $50+$, a population with a high rate of prescription drug use, watch an average of more than 40 hours of live television per week (Nielsen, 2014), the pervasiveness of pharmaceutical advertising could have large effects on prescription drug use. Indeed, Figure 1 shows that the dramatic rise in advertising that occurred over the last two decades has coincided with a striking increase in spending on prescription drugs. Per-capita spending on prescription drugs increased five-fold between 1990 and 2010, following decades of little spending growth (National Health Expenditure Accounts, 2015). While the coincidence of these trends suggests a strong relationship between advertising and spending, the causal channel could go in both directions. The unprecedented number of blockbuster drugs introduced in the 1990s could have induced greater advertising as well as greater drug spending. This, along with other confounding factors, makes it difficult to isolate the independent effect of DTCA.

The rise in the level of DTCA has generated much debate about its effects on patient welfare. Most countries (with the exception of the U.S. and New Zealand) ban this type of advertising. On the one hand, DTCA may be informative if it educates patients about available treatments, encourages individuals to seek care for underdiagnosed conditions, and improves communication between patients and physicians. Advertisements may also serve to remind patients to take their existing medications and influence their perception of the benefits of treatment, promoting better drug adherence (Holmer, 2002; Donohue et al., 2004; Wosinska, 2005). On the other hand, the

\footnotetext{
${ }^{1}$ Prior to 1997 , ads were required to include essentially all of the information on the product label (which is unlikely to fit in a 30-second television or radio spot), but after 1997 only the major risks and benefits needed to be included. Before 1997, most advertising was in print and it was limited.

${ }^{2}$ See Nielsen "Tops of 2014: Advertising" available at: http://www.nielsen.com/us/en/insights/news/2015/tops-of2014-advertising.html

${ }^{3}$ Nielsen estimate reported in FiercePharma "Top 10 DTC Pharma Advertisers - H1 2013" available at: http://www.fiercepharma.com/special-reports/top-10-dtc-pharma-advertisers-h1-2013
} 
persuasive and product differentiation aspects of DTCA may lead to unnecessary treatments and excessive drug spending. There is a lack of consensus on whether DTCA serves primarily to inform or persuade, which matters for assessing its value to patients. This distinction hinges partly on the extent to which DTCA impacts drug utilization and the mechanisms underlying advertising's impacts, such as whether the effects of DTCA stem from changes in the take-up of therapy versus changes in adherence and whether there are spillovers of advertising on nonadvertised drugs. However, identifying DTCA's causal effects on utilization has been challenging empirically, since demand factors could influence both the amount of advertising and the timing of advertisements. Some studies have tried to address these endogeneity concerns with instrumental variable strategies, though it is difficult to find appropriate instruments given the close relationship between demand and advertising decisions.

We address these challenges by providing one of the first quasi-experimental studies on the effects of DTCA on drug utilization. We exploit a large and plausibly exogenous shock to DTCA driven by the introduction of Medicare Part D in 2006. We focus on drugs that treat five chronic conditions that account for a large share of advertising spending-depression, diabetes, hyperlipidemia, hypertension, and osteoporosis ${ }^{4}$ - and estimate effects along both the intensive and extensive margins to examine the causal pathways through which DTCA influences drug utilization. Our instrumental variable strategy exploits variation across geographic areas in the share of the population that is covered by Medicare (ages 65+) to predict changes in advertising exposure across areas. We show that there was a large relative increase in advertising exposure immediately following the introduction of Part D in geographic areas with a high share of elderly compared to areas with a low elderly share. Prior to Part D, both the levels and trends in advertising exposure across high and low elderly share areas were nearly identical.

Since advertising cannot be perfectly targeted to the elderly, we exploit the sudden differential increase in advertising exposure for non-elderly that live in elderly-dominated areas to estimate the effects of advertising on drug utilization. This strategy hinges on the observation that non-elderly individuals are exposed to the increase in DTCA but do not receive Part D insurance coverage, which may independently impact drug utilization. Our focus on the non-

\footnotetext{
${ }^{4}$ Among the 25 most advertised brand-name drugs, these 5 conditions account for half of total advertising expenditures (Kantar Media, 2011).
} 
elderly allows us to isolate the effects of advertising on drug utilization from the direct effects of Part D.

This paper makes four main contributions. First, we exploit a major policy change to identify the effects of DTCA on drug utilization. The use of policy shocks as natural experiments has been scarce in the existing advertising literature, although it is a promising approach for obtaining variation in advertising that is unrelated to individual demand and health status. Second, we use this empirical framework to estimate the effects of DTCA not only on overall drug utilization but also separately on the extensive and intensive margins-i.e., higher take-up of drug treatments versus better drug adherence by existing patients. We tease apart the contributions of these component effects to the total relationship between advertising and utilization to explore welfare implications of advertising. The prior literature has primarily focused on overall utilization. Third, we use data from two novel sources. We measure pharmaceutical advertising using data on Nielsen ratings in local media markets that we observe separately for the non-elderly (under 65) and the elderly (65+). While most of the DTCA literature uses advertising expenditures or the volume of ads to quantify advertising, ratings are a more direct measure of actual advertising exposure. ${ }^{5}$ This measure is more often used outside of the DTCA literature to measure exposure to other types of television programming (e.g., Kearney and Levine, 2014; Kanazawa and Funk, 2001). We obtain measures of drug utilization using administrative pharmacy claims from a database of over 40 large national employers covering about 18 million person-years. Finally, a fourth contribution of our study is to quantify spillover effects of Part D on the non-elderly population. Numerous studies have examined the effects of Part D on the elderly but few have considered the effects on the non-elderly. ${ }^{6}$ One important mechanism through which Part D may have an effect on the non-elderly is through advertising, and we find strong evidence of these spillovers.

We find that drug utilization is highly responsive to advertising exposure. Following Part $\mathrm{D}$, there was a 6 percent increase in the average number of prescriptions purchased by the nonelderly in areas with high elderly share, relative to areas with low elderly share. Event study results using quarterly utilization data show that this differential effect coincided precisely with

\footnotetext{
${ }^{5}$ To our knowledge, Saffer et al. (2007) - which studies advertising for nicotine replacement therapy - is the only other pharmaceutical advertising study to use Nielsen ratings data.

${ }^{6}$ Part D may also have spillover effects on the non-elderly through pharmaceutical R\&D investments (BlumeKohout and Sood, 2013) and negotiated drug prices (Duggan and Scott Morton, 2010; Lakdawalla and Yin, 2015).
} 
the implementation of Part D in 2006 and persisted through the end of our study period in 2010. The event study also confirms that there were no differential pre-trends in utilization across higher and lower elderly share areas, providing support for the identifying assumption that the trends would have continued to be the same in the absence of Part D. Our results imply that a 10 percent increase in advertising views leads to a 5.4 percent increase in total prescriptions filled for advertised chronic drugs. Our estimate of the elasticity with respect to views exceeds prior estimates of the elasticity with respect to advertising expenditures, which most DTCA studies estimate. This is consistent with prior evidence that an increase in advertising expenditures leads to a less than proportional increase in advertising views (Sethuraman et al., 2011).

We find that advertising increases the take-up of drug treatments and improves compliance for existing patients. Expanded take-up of prescription drugs accounts for about $70 \%$ of the total effect of advertising, while increased use among existing patients accounts for the remaining 30\%. As an important component of this latter effect, we estimate that a 10 percent increase in advertising views increases adherence to a drug therapy by 1 to 2.5 percent. Finally, we assess whether the increase in advertising led simply to substitution from nonadvertised to advertised drugs or whether it generated a net increase in drug utilization for drug classes. We find evidence that advertising also increased the use of non-advertised drugs in the same therapeutic class as an advertised drug. This suggests substantial positive spillover effects on the use of non-advertised drugs within the same drug classes.

The utilization results are robust to geographic area-specific trends, sample restrictions, and alternative specifications of the instrument. We also find little evidence in favor of alternate causal channels. First, Part D did not differentially reduce out-of-pocket drug prices in high elderly share areas, ruling out concurrent price effects that could independently impact drug utilization. Second, changes in direct-to-physician advertising after Part D appear to be unrelated to elderly share. Finally, in a placebo test estimating the differential effects of Part D on drug utilization for classes of drugs that do not advertise, we find effects that are very small or null relative to the effects for classes of drugs that do advertise, providing support that the observed changes in utilization are due to advertising and not driven by other potential spillovers of Part D on the non-elderly (e.g. through changes in physician prescribing behavior).

While the literature on prescription drug demand has focused heavily on the importance of prices and insurance status in explaining utilization patterns, we generate estimates of the 
responsiveness of drug demand to a non-monetary factor and find economically important effects. Using the range of price elasticities in the literature (Goldman, Joyce, and Zheng, 2008) combined with our main results, our estimates imply that a 10 percent increase in advertising exposure generates a change in prescription drug utilization equivalent to a 9 to 27 percent reduction in out-of-pocket price. This paper also shows that by increasing insurance coverage for one population, Part D had the effect of generating additional demand for individuals outside of the Medicare program. These demand increases were themselves large and economically important.

The rest of the paper proceeds as follows. Section 2 presents background on Part D and the mechanisms for its effect on advertising, as well as a review of the related DTCA literature. Section 3 describes the data sources. Section 4 outlines the empirical framework. Section 5 presents the results. Sections 6 and 7 provide a discussion and conclude.

\section{Background and Related Literature}

\subsection{Why Should Medicare Part D Increase Advertising Exposure?}

Medicare is a federal program that provides health insurance to the elderly, ages 65 and over, and to qualifying non-elderly disabled individuals. On January 1, 2006, Medicare expanded to include coverage of outpatient prescription drugs through the introduction of Part D. Part D was enacted as a provision of the Medicare Modernization Act (MMA), which was signed into law in December of 2003, and represented one of the largest expansions of the Medicare

program since its inception. Part D substantially increased the proportion of elderly with drug insurance and as a result lowered average out-of-pocket drug costs for Medicare beneficiaries. Previous research has shown that this price reduction increased drug utilization among the 65+ population (e.g. Ketcham and Simon, 2008; Yin et al., 2008; Lichtenberg and Sun, 2007).

The widespread changes brought about by Part D may have significantly altered pharmaceutical firms' incentives to advertise. As shown in earlier theoretical work (Lakdawalla, Sood, and Gu, 2013), insurance expansions such as Part D can influence the return to advertising through two mechanisms. First, both theory and prior empirical literature suggest that more profitable markets generate greater returns to capturing new consumers, and in turn stimulate more intense advertising effort. Thus, the returns to advertising are higher when there are more 
insured consumers in the market, because insured consumers face lower out-of-pocket costs that induce greater use and spending. Second, insurance coverage might alter the responsiveness of consumers to advertising at the margin. If insured consumers are more responsive, firms will face greater incentives to advertise. Indeed, prior empirical studies suggest that better insured consumers are more responsive to advertising (Wosinska, 2002). Intuitively, an undecided consumer might be more likely to try a new drug after being exposed to advertising if the cost of trying the new drug is lower. Taken together, these two effects suggest that insurance expansions strengthen incentives for advertising and we show that this prediction is borne out in the data.

Given this result, we would expect drug advertising to increase more in geographic areas with a higher share of elderly individuals (relative to areas with a low share of elderly), which experienced a greater expansion in insurance coverage. Consistent with this idea, previous research (Lakdawalla, Sood, and Gu, 2013) found that Part D led to a large relative increase in national DTCA spending for drugs differentially used by Medicare beneficiaries. That paper, which focused primarily on the effects of Part D on advertising, also suggested scope for utilization effects of advertising using the Medical Expenditure Panel Survey (MEPS). We build on this previous work, by exploiting a new strategy based on geographic variation in elderly shares. The geographic variation allows us to control for drug-specific shocks, which is of particular importance during our study period given a wave of patent expirations and black box warnings. We also use health insurance claims data to better identify and characterize the causal effects of advertising along both the intensive and extensive margins.

\subsection{Previous Literature on Advertising Effects}

Our paper contributes to a large literature on the impacts of DTCA on drug utilization (see Dave, 2013 for a recent survey). The majority of studies in this literature find positive demand effects of advertising. Although studies consistently find evidence of significant market expansion effects from advertising (e.g. Rosenthal et al., 2003; lizuka and Jin, 2005; Bradford et al., 2006; Shapiro, 2015), evidence of market stealing-gaining market share from competitors - is mixed. Some studies find no effect, and others find small but statistically significant effects (e.g. Wosinska, 2002; Dave and Saffer, 2012). In general the market expansion effects appear to dominate. 
Evidence from consumer and physician surveys find that advertising increases the likelihood that a patient initiates a request for a specific drug treatment and the likelihood that physicians fulfill these requests (Hollon, 2005). In one randomized controlled trial, actors are sent to doctors' offices presenting symptoms of depression. Those who asked for a specific drug treatment or general treatment for depression related to an ad they saw on television were significantly more likely to be prescribed an anti-depressant relative to those who did not request treatment (Kravitz et al., 2005). The magnitude of the effects ranged from 53-76\% for those requesting treatment relative to $31 \%$ for those not requesting treatment.

A persistent challenge for the literature on the impact of advertising on drug utilization has been in identifying a source of variation in advertising that is orthogonal to demand factors. ${ }^{7}$ Our study overcomes this problem by using a natural experiment - the introduction of Part Dto study the effects of DTCA on drug utilization among those unaffected by the insurance expansion. To our knowledge, the only other study that provides natural experiment evidence using policy variation is a working paper by Sinkinson and Starc (2015), which exploits changes in advertising due to political election cycles (which temporarily displace DTCA), to examine the effects of own and rival advertising on firm revenue. The estimated elasticities in our study tend to be larger. This may be partially explained by the differences in identification strategies, with Sinkinson and Starc (2015) exploiting temporary reductions in advertising and our study exploiting a permanent increase. Given the long-lasting effects of advertising, we might expect that temporary reductions in advertising intensity would lead to smaller effects on use. In another related working paper, Shapiro (2015) uses variation in advertising expenditures at discrete television market boundaries to estimate the effects of changes in advertising on drug utilization. This strategy assumes that trends in utilization across border-counties are not systematically related to advertising changes and that demand shocks that drive advertising differences are not disproportionately located along one border—assumptions that are difficult to test.

\footnotetext{
${ }^{7}$ Most previous studies of DTCA have had to rely on cross-sectional or time-series variation in advertising expenditures to identify the effect on drug utilization. Studies that attempt to address the endogeneity concern have instrumented for DTCA using variables such as the age of the drug, time until patent expiration, advertising expenditures by the same company in an unrelated drug class, and national advertising costs.
} 
Our study offers several other innovations over the prior literature. First, we use data that measure actual exposure to advertising using Nielsen ratings (discussed below) rather than relying on proxies such as advertising spending or number of ads aired. Nearly all DTCA studies use advertising expenditures or volume to quantify advertising. One exception is Avery, Eisenberg, and Simon (2012), which uses survey data from Simmons National Consumer Survey and Kantar/TNS Media Intelligence to construct individual-level exposure to ads for antidepressants. In contrast to that paper, which uses self-reported anti-depressant use in the past 12 months, we have administrative pharmacy claims that enable us to construct comparatively rich measures of utilization such as total prescriptions and days supplied.

Second, we estimate the effects of advertising on take-up of treatment and medication adherence, and evaluate how these component effects independently drive the overall relationship between advertising and drug utilization. Since much of the pharmaceutical advertising literature has focused on total utilization effects, little is known about the mechanisms that underlie the relationship between drug utilization and advertising. Specifically, there is little empirical evidence on the effects of advertising on drug adherence and the few existing studies find very small or null effects (Donohue et al. 2006; Wosinska, 2005). Understanding the components of the drug utilization effect is needed to begin to assess whether the increase in use induced by DTCA is welfare enhancing.

Finally, we estimate the effects of DTCA for a large number of brand-name drugs across several conditions. Prior studies often focus on a single drug class or a small subset of brandname drugs. Given that FDA policy tends to consider all types of prescription drugs uniformly, our estimates are likely more generalizable for such policy considerations.

\section{Data Sources}

\subsection{Advertising Data}

The data on viewership of pharmaceutical ads in local media markets come from the Nielsen $\mathrm{Ad}^{*} \mathrm{Views}^{\mathrm{TM}}$ database from 2001-2010. We focus on television advertising, which accounts for more than two-thirds of total DTCA expenditures (Avery, et al., 2012). Nielsen collects data on the universe of television commercials shown in 210 "Designated Market Areas" (DMAs) that span the entire United States. Each DMA is comprised of one or more counties in which the 
home market television station holds a dominance of total hours viewed. ${ }^{8}$ Nielsen viewing stations located in each DMA record all commercials shown and can identify "national" ads shown in all 210 DMAs and "local" ads shown in a subset of these markets. We use data on local ads since there is scope for targeting different amounts of advertising to different markets. Local ads can be shown during network programming (e.g. NBC), syndicated programming, or local television programming (e.g. local news). We obtained local advertising data for the top 100 DMAs (86.5\% of TV viewers) and the top 200 advertised brand-name prescription drugs from 2001-2010, which account for more than $96 \%$ of advertising spending.

Our measure of DTCA exposure is Nielsen rating points. Rating points are derived from data collected on actual viewership of television commercials for a sample of television-owning households in each DMA. Using meters attached to participants' televisions or paper diaries, Nielsen records who in the household is watching and what they are watching 24 hours a day. "Rating points" are simply the fraction of the sample that watched a particular commercial. In our data, we observe rating points for each brand-name prescription drug, DMA, quarter, and for two age groups (ages 2-64 and ages 65+), which is defined as follows:

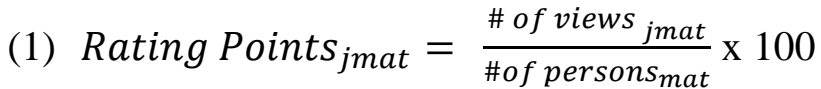

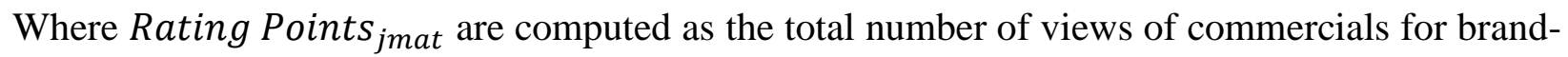
name drug $j$ in market (DMA) $m$, in age-group $a$, and in quarter $t$ divided by the total number of individuals in the sample in market (DMA) $m$, in age-group $a$, and in quarter $t$, multiplied by 100. We divide rating points by 100 in order to interpret this measure as average views per person. Rating points for a brand can increase if the number of commercials increases, the commercials become better targeted (e.g. primetime vs. late night), and/or more individuals in the market watch television. Nielsen rating points are the industry standard for measuring television viewership and have the advantage of being a more direct measure of advertising exposure than total advertising expenditures or the number of ads, which have been the predominant measures of advertising in the DTCA literature to date. ${ }^{9}$

\footnotetext{
${ }^{8}$ For example, the Los Angeles DMA contains 8 counties in the surrounding area which have relatively homogeneous television programming.

${ }^{9}$ Nielsen collects very limited data on advertising expenditures at the local level. Expenditure data is not available for local commercials shown during network or syndicated programming, which comprise the majority of local
} 
While in recent years, a variety of alternative methods for watching television programming have been introduced - such as time shifted viewing (e.g. DVR) and Internet viewing - traditional live television still remains the dominant medium. In the third quarter of 2014, adults ages 50-64 watched on average 43.2 hours of television programming per week, of which only 3.8 hours were time-shifted and an additional 1.2 hours were spent watching video on the Internet (Nielsen, 2014). Since most of our study period from 2004-2010 precedes the widespread adoption of time-shifted viewing and the introduction of Netflix, YouTube, Hulu, and other Internet streaming services, we expect that the share of our sample that is not watching television live is very small. Moreover, Nielsen does account for most time-shifted viewing in its rating points by including views of all recorded programming watched within seven days of its initial release.

\subsection{Drug Utilization Data}

We construct measures of drug utilization using a database of insurance claims from more than 40 large national employers, including many Fortune 500 companies, for 2004-2010. ${ }^{10}$ These data were compiled by a prominent health benefits consulting company and cover approximately 18 million person-years during the study period. The claims dataset is described in more detail in several previous studies (e.g. Goldman et al., 2004; Goldman and Joyce, 2007; Joyce et al., 2007).

The pharmacy claims include detailed information about all outpatient prescription drug purchases including the drug name, National Drug Code (NDC), days supplied (e.g. 30 days, 60 days, etc.), and payments. We link the claims data by NDC with data from IMS Health to obtain consistently defined drug names and therapeutic drug classes for each prescription. Limited demographic information is provided on the claims, including gender, age, marital status, and the three-digit ZIP code of residence.

We restrict our analysis to individuals with full-year insurance coverage and aged 40-60. ${ }^{11}$ This group is closer in age to Medicare eligibility and thus more likely to be using similar types

commercials. Only commercials shown during "local television" programming (e.g. local news) have expenditure data. For this reason, we do not use expenditure data in this study.

${ }^{10}$ Data from this company prior to 2004 is not defined in a consistent way with data from 2004 onwards, thus we cannot use it in our analysis.

${ }^{11}$ We exclude ages 61-64 out of concern that individuals close in age to Medicare eligibility may change their drug utilization behavior in anticipation of future Part D coverage (Alpert, 2015). 
of prescription drugs as Medicare beneficiaries. We only include individuals who live in the top 100 Nielsen DMAs, which represents about 95 percent of pharmacy claims.

We use the three-digit ZIP code to match the claims data with the Nielsen advertising data. Each person in the claims data is assigned to a local advertising market (DMA) based on their ZIP code of residence to determine their potential advertising exposure in each quarter. One limitation of our data is that Nielsen DMAs are defined in terms of five-digit ZIP codes, while we only observe individuals' three-digit ZIP codes in the claims. Some three-digit ZIP codes overlap multiple DMAs, so it is not possible to assign these individuals to a single DMA with certainty. Instead we assign these individuals the population-weighted ${ }^{12}$ average of advertising exposure (rating points) across all of the possible DMAs where they could reside. About 30 percent of the individuals in the claims data receive this probabilistic measure of advertising exposure. Consequently, we use the three-digit ZIP code as the effective advertising market rather than the DMA, since advertising exposure is constant within three-digit ZIP codes for all individuals in the sample. As we will show below, effects are similar if we restrict the data to the subsample with a single DMA match.

We initially focus on two variables: total number of prescriptions purchased and total days supplied. We aggregate these measures to quarterly totals for each person by drug. For most analyses, we focus on drugs that treat five chronic conditions: depression, diabetes, hyperlipidemia, hypertension, and osteoporosis. There are 50 drugs for these conditions that were advertised during our study period and are contained in the Nielsen top 200 (see list of drugs in Appendix Table B.1). We collapse the data to the three-digit ZIP code level by condition, to conduct our analyses at the level of variation in advertising exposure. Since Part D affected advertising incentives for all drugs and due to the possibility of spillovers across drugs treating the same condition, we do not conduct a drug-level analysis and instead perform our analysis at the condition-level. This results in 107,345 ZIP code-by-condition-by-quarter observations. In computing mean prescriptions purchased and mean days supplied within a ZIP code and condition, zeros are included for individuals who were enrolled in a health insurance

\footnotetext{
${ }^{12}$ Population weights for the 5-digit ZIP code level come from the 2000 Decennial Census. In the Census, population estimates are aggregated by ZIP Code Tabulation Areas (ZCTAs) and we use a 5-digit ZIP code to ZCTA crosswalk to obtain the 5-digit ZIP code population estimates.
} 
plan but did not purchase any drugs for the condition. ${ }^{13}$ Separate means are computed for advertised and non-advertised drugs ${ }^{14}$ within each of the five chronic conditions. We focus primarily on advertised drugs and use non-advertised drugs in select specifications.

We also construct a measure of drug adherence for individuals who filled at least one prescription for any of the five chronic conditions. We measure adherence between the quarter of the individual's first drug claim through the quarter of their last drug claim for that condition. ${ }^{15}$ We consider adherence as receiving continuous treatment for a condition, ${ }^{16}$ rather than for a specific brand since this is the more relevant dimension from a policy and welfare perspective. Adherence is measured quarterly and separately for each condition as the medication possession ratio (MPR), which is a widely used method for measuring medication compliance with claims data (Peterson, et al., 2007; Hess, et al., 2006). The MPR is calculated as the number of days with drug on-hand (i.e. days supplied) divided by the number of days in the quarter.

We adjust the numerator of the MPR to account for claims with overlapping days supplied. For example, it is typical to refill a prescription before finishing the days supplied for the initial prescription. The extra days supplied during the overlap period may not indicate better drug adherence. If overlapping claims have the same active ingredient, ${ }^{17}$ we assume that the person finishes the days supplied in the first claim before starting the days supplied in the second claim. A refill of an existing medication or a switch from a brand name to generic product would fall under this category. For overlapping claims with different active ingredient names (for the same condition), we assume that patients start using the days supplied for the second claim on the fill date and throw away the remaining days supplied for the first claim. This case likely represents a drug switch that resulted from an unsatisfactory response to the initial medication. Since

\footnotetext{
${ }^{13}$ In other words, in the individual-level data, each person gets 5 observations for each of the conditions in each quarter whether or not they were diagnosed with the condition. If they do not use a drug for that condition, the observation is zero. We do not condition on having a diagnosis as advertising might affect the rate of diagnosis.

${ }^{14}$ Non-advertised drugs (typically off-patent brands or generics) are drugs that belong to the same therapeutic drug classes as the 50 advertised chronic brand-name drugs, but do not advertise during our study period.

${ }^{15}$ In some specifications, we account for discontinuation by computing an alternative measure of adherence where we assume that a person is non-adherent after their last observed drug claim.

${ }^{16}$ Specifically, we combine utilization for advertised drugs with the non-advertised drugs in the same therapeutic classes as the advertised drugs.

${ }^{17}$ Combination drugs are viewed as a unique combination of two or more active ingredients.
} 
advertising may lead to more drug switching, it is especially important to account for this case to avoid overstating the effect of advertising on adherence. ${ }^{18}$

After constructing the quarterly MPR for each individual by condition, we also create a binary indicator for individuals who had MPR $\geq 80 \%$, which is considered high adherence and is the threshold most commonly reported in the pharmaceutical literature (Andrade, et al., 2006). As before, we collapse the data by three-digit ZIP code, condition, and quarter, computing the mean MPR and the proportion of individuals with MPR $\geq 80 \%$ in each cell.

\subsection{Population Data}

We compute the share of the population that is 65 and over (i.e. eligible for Medicare) in each local advertising market (DMA) using the 2000 Census. From the advertiser's perspective, the DMA is the relevant market. For individuals who cannot be matched to a single DMA, they are assigned the population-weighted average of the elderly share across all possible DMAs where they could reside. There is substantial heterogeneity in the share of the population that is $65+$ across markets, ranging from 8\% in the Houston DMA to 26\% in Fort Myers-Naples DMA (see Table 1). The elderly share is used to construct the instrument. This share is held constant at the DMA's 2000 value so that no identification originates from changes in the elderly share.

\subsection{Descriptive Statistics}

In Table 2, we present sample means for the advertising variables by elderly share for 2005 and 2007, before and after Part D. For each year, we split the 100 DMAs into above-median elderly share markets and below-median elderly share markets. Average views per person of pharmaceutical ads are much greater for elderly viewers (ages 65+) relative to non-elderly viewers (ages 2-64). For example, in low elderly share markets in 2005, elderly viewers saw on average 1,184 pharmaceutical ads per year compared to 387 ads for non-elderly viewers. This difference is likely driven by the targeting of pharmaceutical ads to programming that elderly viewers watch, as well as the fact that older viewers watch more hours of television per year. Comparing the change in views per person from 2005 to 2007 across market types, we observe a

\footnotetext{
${ }^{18}$ Days in the hospital were assumed to be fully compliant and patients resumed their prescriptions after they were discharged.
} 
three to five times larger increase in ads viewed in high elderly share markets for elderly and non-elderly viewers following Part D.

Table 2 also reveals differences in the average population size across high and low elderly share markets. High elderly share markets tend to be less populated than low elderly share markets. This may be partially due to retiree preferences for less urban areas. This result suggests that it will be important to include market fixed effects in all of our analyses.

\section{Empirical Strategy}

To understand the impact of DTCA on drug utilization, we exploit quasi-experimental variation in advertising exposure after the introduction of Part D for non-elderly adults living in high elderly share areas. Specifically, we capture the differential change in DTCA exposure across high and low elderly share areas by estimating the following difference-in-difference equation, our first-stage relationship:

(2) DTCA $_{m c t,<65}=\beta\left({\text { Share } 65_{m}} \times\right.$ Post $\left._{t}\right)+\gamma_{t}+\mu_{m}+\alpha_{c}+\epsilon_{m c t}$

Where $D T C A_{m c t,<65}$ is average views per person (rating points) for non-elderly individuals ages 2-64 in market $m$ in quarter $t$ for ads related to condition $c$. The market $m$ is the three-digit ZIP code. $^{19}$ Share $65_{m}$ is the share of population $65+$ in market $m$ in $2000^{20}$, and Post $t$ is an indicator that equals 1 in the post-Part D period (2006-2010). Thus Share65 ${ }_{m} \times$ Post $_{t}$ is our instrument for DTCA exposure for the non-elderly. In some specifications we use an alternative form of this instrument, HighElderlyShare ${ }_{m} \times$ Post $_{t}$, where HighElderlyShare His $_{\text {an }}$ indicator that equals 1 if the market $m$ has an above-median elderly share. This instrument does not restrict the impact of elderly share to have a linear relationship with advertising but, instead, considers the possibility of non-linear effects. We use the share of the population $65+$ rather

\footnotetext{
${ }^{19}$ As discussed in Section 3.2, we collapse the data to the 3-digit ZIP code level rather than the DMA-level, since a subset of the sample resides in 3-digit ZIP codes that cross multiple DMAs and cannot be matched to a single DMA. We assign these individuals the population-weighted average advertising exposure across all the DMAs where they might reside. Thus, our constructed advertising exposure measure is constant within 3-digit ZIP codes, but not always within DMAs.

${ }^{20}$ The $65+$ share is also computed at the DMA level since this is the relevant market from the advertiser's perspective. For individuals whose 3-digit ZIP code cannot be matched to a single DMA, they receive the population weighted average of the $65+$ share across all the DMAs where they might reside.
} 
than the level $65+$ as our instrument to reflect advertising incentives. The cost of advertising is based on the total number of viewers in a market, so the cost per elderly viewer is lower in markets with a high elderly share. Thus, we would expect that firms targeting elderly viewers would advertise more in high elderly share markets. Since geographic areas with a high concentration of elderly are potentially different from areas with a low concentration, all of our analyses condition on market fixed effects, which account non-parametrically for cross-sectional differences by elderly share. We also include time fixed effects to account for secular time trends and condition fixed effects to account for differences in utilization and returns to advertising across conditions. Standard errors are clustered at the three-digit ZIP code level (market $m$ ) to account for serial correlation within areas as well as correlation across conditions within areas.

Next, we estimate a reduced form equation comparing changes in drug utilization for the non-elderly across areas with a high elderly share relative to a low elderly share. By focusing on the non-elderly population, we can isolate the effects of advertising on drug utilization from the direct effects of Part D on utilization. The equation for the reduced form is as follows:

(3) $Y_{m c t,<65}=\theta\left({\text { Share } 65_{m}} \times\right.$ Post $\left._{t}\right)+\rho_{t}+\sigma_{m}+\tau_{c}+\epsilon_{m c t}$

Where $Y_{m c t,<65}$ is mean total prescriptions or days supply for non-elderly individuals in market $m$ in quarter $t$ for advertised drugs that treat condition $c$. We also use this reduced form model to estimate effects on other measures of drug utilization including prescriptions purchased (or days supplied) conditional on use, the probability of any drug use, and drug adherence. We scale the reduced form effect by the first stage to obtain the 2SLS estimate: the effect of advertising on prescriptions purchased. ${ }^{21}$

\footnotetext{
${ }^{21}$ It should be noted that the Nielsen data on advertising exposure is available for the 2-64 age group, while we select on ages 40-60 (individuals who are likely to be using similar drugs as Medicare beneficiaries) in the utilization data. Our advertising elasticity estimates will not be biased by this age-group selection if the proportional change in advertising exposure after Part D is the same across ages. As shown below, individuals 2-64 and 65+ have the same proportional change in advertising exposure after Part $\mathrm{D}$, which supports this assumption.
} 


\section{Results}

Our analysis proceeds in three steps. We first provide evidence that our instrument predicts changes in advertising exposure, a necessary condition for identifying the impact of advertising on drug utilization. Second, we estimate the causal impact of advertising exposure on total drug utilization for the non-elderly using two-stage least squares. Third, we investigate the causal pathways along which advertising operates by decomposing the total utilization effect into intensive and extensive margin effects including drug adherence and take-up.

\subsection{First-Stage Effects of Part D on Advertising Exposure}

\subsubsection{Overall Sample of Drugs}

We begin by showing graphically that the share of the population that is $65+$ in an area is strongly predictive of differential changes in advertising exposure after Part D. Figure 2 plots mean annual views per person (rating points) of ads for the top 200 brand-name pharmaceuticals from 2001-2010, comparing DMAs with above-median and below-median elderly shares. The figures show views by the non-elderly under age 65 . Prior to 2006, both the levels and trends in advertising exposure for the non-elderly are nearly identical across geographic areas. However, after Part D was implemented in 2006, advertising exposure increases sharply for non-elderly living in areas with a high elderly share relative to those living in areas with a low elderly share. This difference persists through the end of the study period. ${ }^{22}$

Since we are following a balanced panel of 200 brand-name drugs, there is a secular downward trend in overall advertising over this time period due to the "aging" of these drugs. This pattern mimics the decline in national advertising expenditures shown in Figure 1. Several of the drugs in our sample lost patent protection over the study period. ${ }^{23}$ Since off-patent drugs typically do not advertise (Dave, 2013), patent expirations reduce aggregate advertising expenditures. If we exclude drugs that lost patent protection during this period (see Panel B of

\footnotetext{
${ }^{22}$ The patterns in advertising exposure are similar for elderly viewers, as seen in Appendix Figure B.1. Prior to Part $\mathrm{D}$, the trends are parallel but there is less advertising exposure in high elderly share areas, perhaps due to the lower rates of drug insurance coverage (and income) in these areas. After Part D, the pattern flips with an immediate relative increase in advertising exposure in areas with a high elderly share.

${ }^{23}$ Notably, there were 4 major patent expirations that occurred around 2006 for four of the top 200 drugs (Pravachol, Wellbutrin XL, Zocor, and Zoloft) as well as a wave of other major patent expirations during the late 2000s.
} 
Figure 2), we instead find an upward trend in overall advertising views. We assume that markets with a low-share of elderly and a high-share of elderly are similarly affected by common nationwide shocks such as those driven by drugs losing patent protection. Given the similar pretrends in advertising exposure across markets, this assumption likely holds.

We estimate the magnitude of this differential change in advertising exposure using a difference-in-difference model similar to Equation 2 at the DMA level (see Appendix Table B.2). Comparing non-elderly individuals in areas with high elderly share to their peers in low elderly share areas, we find that Part D generated an additional 25 ads viewed per year, or about one additional ad every other week. This represents a 6 percent increase from the mean advertising exposure level. ${ }^{24}$ As a point of comparison, we estimate the change in advertising exposure for elderly viewers (ages 65+). For the elderly, the effect of Part D on the number of ads viewed is much larger, as expected, since Medicare beneficiaries are likely the intended target audience for these ads. We find that Part D generated an additional 72 ads viewed per year, or an additional ad every 5 days, for elderly viewers in high elderly share markets relative to their peers in low elderly share markets (see Column 2 of Appendix Table B.2). This represents a 6.3 percent increase relative to the mean for this group.

These results confirm that the introduction of Part D is associated with a large relative increase in advertising exposure for the elderly in high elderly share areas and that there are substantial spillover effects on exposure for the non-elderly. This result is consistent with the hypothesis that Part D increased the returns to advertising more in areas with higher elderly share.

\subsubsection{Chronic Drugs}

While the above results verify a strong relationship between the instrument and advertising exposure for all drugs in our sample, we also assess the predictive power of the instrument for our primary analysis sample of chronic drugs for five conditions (depression, diabetes, hyperlipidemia, hypertension, osteoporosis) that are prevalent among Medicare beneficiaries $^{25}$ and account for a large share of advertising, as described in Section 3.2. Since

\footnotetext{
${ }^{24}$ Using the coefficient from the binary instrument in Appendix Table B.2 and the annual mean for views per person in high elderly share markets in 2005 in Table 2 , we calculate the percentage change as $(6.233 * 4) / 413=0.06$.

${ }^{25}$ These five conditions are among the most common conditions for Medicare beneficiaries: $58 \%$ have hypertension, $45 \%$ hyperlipidemia, $28 \%$ diabetes, $14 \%$ depression, $7 \%$ osteoporosis (CMS, 2012).
} 
these drugs are predominantly used by the elderly, they would likely experience the largest increase in advertising from Part D.

First, we replicate the graphical evidence from above for the chronic drugs sample. In Panel A of Figure 3, we plot mean views per person of ads for the selected brand-name chronic drugs. The data are plotted at the quarterly level and for 2004-2010, which corresponds to the quarterly claims data. Although the quarterly data are somewhat noisier, the patterns are the same as they were for the full sample of drugs. Levels and trends in non-elderly advertising exposure are nearly identical across high and low elderly share areas prior to Part D and then diverge sharply in 2006. In fact, advertising exposure for the non-elderly is greater in high elderly share areas compared to low elderly share areas in every quarter after Part D.

We estimate the analogous difference-in-differences regression model shown in Equation 2. This specification represents the first-stage in our research design. Panel A of Table 3 presents the first-stage results using the "Post" variable interacted with Share 65+ as the instrument, while Panel B interacts "Post" with a binary indicator for above-median elderly share (mirroring the graphical evidence). Consistent with the full sample of drugs, we find a strong relationship between the introduction of Part D and differential changes in advertising of chronic drugs across geographic areas. Using the continuous instrument in Panel A, the results show that a geographic area with a one percentage point higher elderly share experienced an increase in quarterly advertising exposure of 0.06 views per person after Part D (significant at the $1 \%$ level). Panel B compares above-median to below-median elderly share areas and shows markedly similar results. ${ }^{26}$ Comparing high to low elderly share areas, ads viewed for chronic brand-name drugs increased by 8.1 percent relative to the baseline mean. Additionally, the F-statistics for the binary and continuous instruments are 30.86 and 32.69, respectively, which are well above conventionally accepted levels (Stock, Wright, and Yogo, 2002), confirming the power of the instruments.

\subsubsection{Validity of the Instrument}

As evidence that there are no other differential shocks to advertising incentives occurring around 2006, we implement a simple placebo test for our research design by estimating the effect

\footnotetext{
${ }^{26}$ Considering the mean difference between high and low elderly share areas, the continuous instrument estimate implies that moving from an average low to high elderly share area would lead to an increase of $0.25(4 * 0.06358)$ views per quarter. This is similar to the estimate using the binary instrument in Panel B which is 0.35 .
} 
of Part D on exposure to advertising for contraceptive drugs. Since contraceptives are unlikely to be used by the elderly, their advertising should be unaffected by Part D. In fact, we find no differential effect of Part D on advertising exposure for the non-elderly across high versus low elderly share markets, as shown in Figure 4. The levels and trends of advertising exposure for contraceptives across areas are virtually identical before and after Part D. This finding is consistent with Lakdawalla, Sood, and Gu, (2013), who find larger relative increases in national advertising expenditures for drugs with a higher Medicare market share following Part D. Moreover, as we showed above, changes in advertising exposure after 2006 were larger for the elderly compared to the non-elderly, as would be expected if the change in advertising were due to Part D. Taken together, this evidence provides reassurance that Part D, not another confounder, is driving the differential changes in advertising. We provide further evidence that the corresponding estimated utilization effects are not driven by other factors in Section 5.2.

\subsection{Second-Stage Effects of Advertising Exposure on Drug Utilization}

\subsubsection{Baseline Estimates}

Having shown that Part D had a substantial differential impact on advertising exposure for high elderly share markets, we next analyze how non-elderly drug utilization responded to this shock to advertising. First, we graph the trends in total prescriptions purchased by the nonelderly across above-median and below-median elderly share areas in Panel B of Figure 3. We continue to focus on the sample of brand-name chronic drugs. Prior to Part D, drug utilization trends track each other very closely in high and low elderly share areas, but then diverge precisely in 2006 with a relative increase in utilization for non-elderly living in high elderly share markets. ${ }^{27}$ This graph mirrors the patterns in advertising exposure, and provides visual evidence of strong effects of advertising on utilization.

Next, we estimate the reduced form difference-in-differences specification in Equation 3 using the total number of chronic prescriptions purchased by the non-elderly as the outcome variable. The effect of Part D on non-elderly drug utilization is positive and statistically

\footnotetext{
${ }^{27}$ Again, the overall reduction in brand-name chronic drug prescriptions in 2006 is due to patent expirations for these drugs, as patients switched to generic versions. In results not shown, when we exclude the 4 major drugs that went off patent in 2006 (Pravachol, Wellbutrin, Zocor, and Zoloft) from the analysis sample, we find a flatter overall trend in utilization across the period and a similar divergence in trends across high vs. low elderly share in 2006.
} 
significant at the $1 \%$ level for both the continuous and binary measures of elderly share. Column 2 of Table 3 shows that the number of chronic prescriptions filled increased by 4.5 percent after Part D in high elderly share markets relative to low elderly share markets.

We also assess the timing of the utilization effect as well as the common trends assumption, by estimating an event-study regression where the outcome variable is the number of chronic prescriptions purchased. The event-study replaces the Share $65_{m} \times$ Post $_{t}$ variable in Equation 3 with a full set of quarter dummies interacted with the elderly share measure. Each coefficient estimate gives the difference in prescriptions purchased in high elderly share versus low elderly share areas relative to the omitted reference period: quarter 4 of 2005 (the quarter before Part $\mathrm{D}$ begins). These coefficients are reported in Table 4 for both the continuous and binary measures of elderly share. High and low elderly share areas had the same pre-trends in prescriptions purchased, as reflected in the statistically insignificant (and close to zero) coefficients prior to 2006. The coefficients then immediately become positive and statistically significant in quarter 1 of 2006 when Part D begins. The effect persists through the end of the study period and remains relatively constant. These patterns hold for both versions of the instrument. Since these results show that there was an immediate differential utilization response to Part D across areas, any alternative explanation for the utilization effect would need to coincide precisely with the introduction of Part D.

In Column 3 of Table 3, we present instrumental variable estimates for the effect of advertising exposure on total prescriptions filled for brand-name chronic drugs. Panel A shows the 2SLS estimate using the continuous elderly share instrument, while Panel B shows results for the binary instrument. The results suggest that an additional ad viewed would lead to an increase of 0.014 to 0.017 prescriptions filled for a chronic condition among the entire sample of nonelderly individuals. In other words, if an ad were viewed by 59 to 71 individuals, it would result in one additional prescription being filled. ${ }^{28}$ Using the mean for prescriptions filled and ads viewed, the implied elasticity of demand with respect to advertising for chronic drugs is 0.54 .

This estimate cannot be directly compared to previous elasticity estimates in the literature because it measures the responsiveness to advertising exposure, whereas most studies measure responsiveness to advertising expenditures. We would expect that the expenditure elasticities would be smaller if there were diminishing returns to advertising. In this case, additional

\footnotetext{
${ }^{28}$ The estimates are for the continuous and binary instruments, respectively $(1 / 0.017=59$ and $1 / 0.014=71)$.
} 
increases in advertising dollars would lead to less than proportional increases in views. Indeed, in a review of the literature on advertising elasticities for a wide range of consumer products, Sethuraman et al. (2011) show that elasticities measured with respect to advertising views are on average 2.3 times larger than elasticities measured with respect to advertising expenditures. Applying this "conversion factor" to our estimate implies an advertising expenditure elasticity of 0.23 , which is within the range of prior estimates in the DTCA literature. ${ }^{29}$

\subsubsection{Robustness Tests}

Our baseline estimates are not sensitive to trends and sample restrictions, which we show through a series of robustness tests. First, we add ZIP code specific linear trends as an additional test for differential pre-trends across areas. Second, as a sensitivity analysis, we restrict our sample to 2004-2007 in order to exclude the years during and after the 2008 Great Recession. This addresses potential composition changes from layoffs or reduced insurance offerings and take-up. Third, we include only the employers that were continuously in the claims data for all years. Fourth, we test for differential changes in the demographic characteristics of enrollees across high and low elderly share areas.

The results of these robustness tests are presented in Table 5. Each cell represents a separate regression where the reported estimate is the coefficient on the instrument (either the continuous or binary version). We report the reduced form and 2SLS estimates separately. The first row in Table 5 repeats the baseline estimates. In the second row, we add interactions of ZIP code fixed effects and a linear time trend to the model in Equation 3. This specification allows for systematically different trends in drug utilization across higher and lower elderly share markets. Since the results remain quite similar in magnitude and are highly significant, such trends appear not to be exerting substantial influence on our results. This reinforces our descriptive figures and event study analysis, neither of which showed evidence of pre-existing differential trends across high and low elderly share areas.

We also test for whether the composition of the claims sample changed before and after Part D differentially across areas with high and low elderly shares. Differential composition changes that are correlated with drug utilization would bias our estimates. We implement three

\footnotetext{
${ }^{29}$ See for example, Berndt et al., 1995; Rosenthal et al., 2003; Kalyanaram, 2009; Dave and Saffer, 2012; Sinkinson and Starc, 2015.
} 
tests for sample composition changes. First, we consider changes in the composition of the claims data due to the 2008 Great Recession. We observe a decline in the number of firms and the average number of employees in each firm beginning in 2008, which suggests that firms are laying off workers, discontinuing health insurance benefits, and/or workers are reducing their take-up of insurance. Workers remaining in our sample during the recession may be observationally different than those in the pre-recession sample. However, this is only a concern to the extent that these composition changes are differentially occurring across high versus low elderly share markets. Row 3 of Table 5 shows the reduced form and 2SLS estimates excluding the recession years 2008-2010. The results are robust to this exclusion verifying that changes in the composition of the sample were not differential by elderly share.

Second, we evaluate the effects of firm churn in the claims data more generally. Out of the 41 firms that we observe in the claims data, 13 firms are observed (i.e. were clients of the health benefits consulting firm) in all seven years of the study period. These firms account for about 50 percent of drug claims. On average, we observe firms for five (typically) consecutive years. In row 4 of Table 5, we re-estimate the drug utilization results using only the firms that were continuously in the sample in all years. The results are very similar to the baseline estimates, although the precision is reduced slightly due to the smaller sample size.

Third, we examine whether individual characteristics change around Part D differentially across high and low elderly share markets. Given the lack of detailed information about demographic characteristics in the claims data, we assign each person the average characteristics of their three-digit ZIP code of residence using the 2000 Decennial Census. ${ }^{30}$ In Appendix Figure B.2, we plot average demographic characteristics (median income, percent black, percent with high school education, and percent with more than high school education) for the entire non-elderly sample across high and low elderly share markets. ${ }^{31}$ While there are small composition changes throughout the time period, we do not observe any large differential changes in the demographic characteristics of the sample, and especially not around the

\footnotetext{
${ }^{30}$ We obtain census characteristics at the ZIP Code Tabulation Area (ZCTA) level. Average characteristics at the 3digit ZIP code level are the population-weighted average across the ZCTAs within the 3-digit ZIP code.

${ }^{31}$ The average characteristics for each ZIP code are held constant at 2000 levels, so any observed changes in characteristics over the sample period come from shifts in the sample towards more or less disadvantaged ZIP codes. Also, given the sample restriction that we only include individuals with full-year insurance coverage, the average characteristics are constant within a year.
} 
introduction of Part D. Together, these three tests strongly suggest that composition changes in the claims data are not driving the observed differential changes in drug utilization.

\subsubsection{Alternative Explanations for Utilization Effects}

In this section, we assess the significance of possible alternative explanations for the observed trends in drug use for the non-elderly. Specifically, we test whether Part D led to: 1) differential reductions in drug prices across high and low elderly share areas; 2) differential changes in physician prescribing behavior for non-elderly patients; and 3) increased detailing efforts that were differentially targeted across DMAs. As shown below, we do not find any evidence to support these alternative hypotheses.

We first examine whether pharmaceutical firms lowered drug prices more in areas with a higher elderly share after Part D, which could lead to a differential increase in drug utilization. Previous studies found that national retail prices declined after Part D for drugs that are most commonly used by Medicare beneficiaries due to the increased bargaining power of insurers (Duggan and Scott Morton, 2010; Lakdawalla and Yin, 2015). However, it is not known: whether these retail price reductions were passed along to patients in the form of lower copays, which is ultimately what determines consumer drug demand; whether out-of-pocket price reductions for the elderly "spilled over" to the non-elderly; and whether out-of-pocket prices declined more in areas with a higher elderly share. Our main specification (Equation 3) presumes that any price effects did not disproportionately affect high elderly share areas, and we can test this assumption explicitly in our data.

Using the claims data, Figure 5 plots trends in average out-of-pocket prices for the nonelderly across high and low elderly share areas. We compute the average out-of-pocket price for each advertised chronic brand-name drug in each ZIP code and quarter at the level of the National Drug Code (NDC). ${ }^{32}$ Using the NDC ensures that the features of the product remain constant over time. It appears that there is a slight overall increase in out-of-pocket prices after Part $\mathrm{D}$, though there is no differential effect across geographic areas around the implementation

\footnotetext{
${ }^{32}$ The NDC is a unique eleven-digit identification number assigned by the FDA to every drug product in the United States. The digits correspond to the manufacturer ID, strength, dosage, and formulation of the product, and the package size. Each brand-name drug is typically associated with multiple NDCs.
} 
date. $^{33}$ Since we observe out-of-pocket prices only for drugs that are purchased, it is possible that the price trends reflect movements in the composition of drugs purchased towards newer, more expensive, products. To address this, in Panel B, we restrict the sample to a balanced panel of NDCs that are observed in every quarter. ${ }^{34}$ Again, we observe an increasing trend in out-ofpocket prices and, importantly, no differential trends across high and low elderly share areas. Thus, we find little evidence that the drug utilization patterns can be explained by price changes.

Second, we consider the possibility that there were other spillovers of Part D on the nonelderly, unrelated to advertising, such as changes to physician prescribing behavior. Part D increased the volume of prescriptions written for the elderly, which may influence prescribing habits, leading physicians to write more prescriptions for their non-elderly patients as well. ${ }^{35}$ To test for this possibility (and other types of spillovers from Part D on the non-elderly), we compare drug utilization across areas for drug classes that advertised during the study period relative to drug classes that did not advertise. If increased utilization by the non-elderly were driven by spillovers unrelated to advertising, we would expect to see increases in utilization for all drug classes (whether or not they advertised).

Figure 6 compares non-elderly drug utilization before and after Part D across high and low elderly share markets for both advertised and non-advertised drug classes. For this test we draw from the full sample of drug classes, not only the five chronic conditions we analyzed previously. We identify 43 drug classes that had a positive amount of advertising ${ }^{36}$ during the study period, and the remaining 52 drug classes did not advertise. ${ }^{37}$ We restrict the sample to the top 10 most widely used advertised drug classes and top 10 non-advertised drug classes among

\footnotetext{
${ }^{33}$ The sawtooth pattern in the figure results from non-linear insurance contracts, which generate higher cost-sharing at the beginning of the year and lower cost-sharing at the end of the year, once deductibles and stop-loss thresholds have been met.

${ }^{34}$ We restrict the sample to 2004-2007 to maximize the number of NDCs that we can include in the balanced panel.

${ }^{35}$ For example, by prescribing more drugs to elderly patients, a physician may learn more about the drugs' therapeutic benefits, leading to more prescribing of successful treatments to all patients. Physicians might also develop prescribing habits based on the increased volume of elderly prescribing which spills over to other patients. ${ }^{36}$ We use the first two digits of the GPI code (available from IMS Health) to identify major classes of drugs. The advertised drug classes are those associated with the 200 advertised brand-name drugs included in our Nielsen sample. Since these 200 drugs represent $96 \%$ of local advertising spending, this represents a virtual census of advertised drug classes.

${ }^{37}$ Advertising is related to the amount of generic penetration in the drug class. For example, among antihyperlipdemics, a widely advertised class of drugs, 26 percent of the claims in our sample are for generics. On the other hand, diuretics, which have been available for decades and have almost a 100 percent share of generic claims, saw no advertising during the study period.
} 
individuals ages 40-60 in order to ensure that the drugs classes are relevant for the non-elderly population (see Appendix Table B.3 for the list of included drug classes).

We find a large relative increase in the use of advertised drugs in high elderly share markets immediately following Part D, but we observe only a very slight increase in the use of non-advertised drugs. Using a triple-difference regression which is analogous to the graph (see Table 6, Panel B), we find that the utilization effect for non-advertised drugs is in fact close to zero and statistically insignificant. Meanwhile, the effect for advertised drugs is large and statistically significant at the 1 percent level. Using the continuous instrument for the elderly share in Panel A of Table 6, we find a small positive effect of Part D on utilization of nonadvertised drugs, but the effect for advertised drugs is more than five times as large. Even the proportional change relative to the mean is much smaller for non-advertised drugs. The substantially larger effects of Part D on utilization for advertised drug classes compared to nonadvertised drug classes, suggests that the observed increase in utilization is driven by advertising, rather than other types of spillover effects, such as physician prescribing behavior, which would lead to increases in the use of advertised and non-advertised drugs alike.

Finally, we assess whether pharmaceutical "detailing" (promotional activity directed to physicians) may have increased differentially across areas after the introduction of Part D. Since Part $\mathrm{D}$ increased the returns to advertising to both consumers and physicians, it is possible that there was also an increase in detailing efforts in DMAs with a high concentration of elderly. Depending on whether detailing is a substitute or complement for direct-to-consumer advertising, this could bias our findings towards or away from zero. A previous study showed that detailing and direct-to-consumer advertising are not geographically correlated. Shapiro (2015) found, in the context of anti-depressants, that DMA-level direct-to-consumer advertising was uncorrelated with detailing in 2001-2003. Moreover, he found that the large and sudden rise in direct-to-consumer advertising following the 1997 change in FDA regulations did not lead to a trend break in detailing at the national level. We reach similar conclusions in our setting.

While we are unable to directly observe detailing data at the DMA level, we conduct an indirect test for Part D's effect on detailing by exploiting within DMA variation in elderly shares. Direct-to-consumer advertising does not vary within a DMA, because local television station signals reach all households. Detailing, however, is more localized since pharmaceutical sales representatives can target individual physicians or practices. In other words, detailing efforts are 
not constrained by DMA boundaries and should respond to more local demand shocks. If detailing responded to Part D, we would expect to observe a larger increase in detailing, and consequently, utilization, in localized areas (e.g. ZIP codes) with a higher share of elderly within a DMA. Thus, if utilization increases due to Part D operates partially through detailing, we would expect changes in utilization within the DMA to be correlated with local elderly shares.

To test this hypothesis, we estimate the reduced form Equation 3 with elderly shares computed at the three-digit ZIP code level, instead of the DMA level, and include DMA $\mathrm{x}$ quarter fixed effects so that identification originates only from variation in elderly share within DMAs. If within-DMA variation plays no role, then inclusion of the DMA $x$ quarter fixedeffects should wipe out the estimated effects on utilization. This test is meaningful because within-DMA variation in elderly share is significant. For example, in the Tampa-St. Petersburg (Sarasota) DMA, the three-digit ZIP code elderly share ranges from $11 \%$ to $27 \%$.

The results of this test are presented in Table 7. Column 1 reproduces the baseline reduced form results (computing elderly share at the DMA level) using only ZIP codes that can be uniquely matched to DMAs. The results are very similar to the main results in Table 3. Column 2 reproduces our results using elderly share computed at the three-digit ZIP code level instead of the DMA level. The effects of ZIP code-level elderly share on total prescriptions are of a roughly similar magnitude as the effects of DMA-level elderly share. ${ }^{38}$ Since DMA and ZIP code elderly shares are correlated, the consistency of these results is not surprising. The main test is presented in Column 3, which adds DMA x quarter fixed effects. Here, the effect of the ZIP code-level elderly share goes to zero and becomes statistically insignificant for both instruments. $^{39}$ This shows that utilization did not respond to Part D differentially by elderly share within DMAs, which is suggestive evidence that detailing did not change after Part D or, at a minimum, that detailing responses were unrelated to elderly share.

This lack of a response is consistent with the nature of detailing, which may be more "sticky" than direct-to-consumer advertising. An increase in detailing requires an increase in physicians' time allocated to sales calls, hiring additional sales representatives, and/or displacing promotions for other pharmaceutical products. In contrast, additional direct-to-consumer ads can

\footnotetext{
${ }^{38}$ Column 2 is using a noisier measure of the relevant elderly share variable and, indeed, we find that the estimate is attenuated in Panel A. The Panel B instrument is dichotomous so classical measurement error results do not apply.

${ }^{39}$ The standard errors in Columns 2 and 3 are nearly the same such that the absence of an estimated effect in Column 3 is not due to increased noise or a relative lack of intra-DMA variation.
} 
be purchased almost instantaneously. ${ }^{40}$ While we cannot eliminate the concerns about detailing entirely, we find it reassuring that detailing changes after Part D appear to be unrelated to elderly share.

\subsection{Potential Welfare Implications}

Given the substantial effect of advertising on total drug utilization, we decompose the overall utilization effect to quantify the various causal pathways from advertising to utilization. These results have important welfare implications from both the consumer and firm perspectives. We conduct three analyses. First, we decompose the total utilization effect into the extensive and intensive margins to understand advertising's role in inducing take-up of drugs versus greater use among existing users. Second, we examine the effects of advertising on drug adherence, a special case of the intensive margin effect. Third, we estimate whether there are positive spillovers of advertising on non-advertised drugs in the same drug class.

\subsubsection{Extensive vs. Intensive Margin Effects}

In Table 8, we present 2SLS estimates for extensive and intensive measures of prescription drug use for chronic drugs. We estimate each specification separately for the full sample and the pre-recession years 2004-2007. We estimate three margins of adjustment for drug utilization: extensive margin effects (any prescription drug use), intensive margin effects (number of prescriptions or days supplied conditional on use), and total effects combining both margins. Columns 1-4 estimate total effects. Columns 1 and 2 repeat the baseline estimates from Table 5 of total prescriptions purchased (including zeros for those who do not purchase any chronic drugs). In Columns 3 and 4, the dependent variable is days supplied of the prescription (e.g. 30 days, 60 days, etc.), including zeros. Days supplied provides a more standardized measure of the units of a prescription across different types of drugs. In Columns 5 and 6, we estimate extensive margin effects as the probability of any use of a chronic drug. Finally, we also estimate intensive margin effects in Columns 7-10: total prescriptions purchased and days supplied, conditional on use. We find positive effects of advertising for all of the outcome variables. The coefficients are statistically significant at the $1 \%$ or $5 \%$ level in all but two

\footnotetext{
${ }^{40}$ The fact that we observe an immediate utilization response after Part D also suggests that direct-to-consumer advertising is the main driver of the effect, since detailing would be expected to adjust with a lag.
} 
specifications. The positive intensive margin effects suggest an effect of advertising on drug adherence, which we explore more explicitly below. We perform a decomposition exercise to compare the relative magnitude of intensive and extensive margin effects (the details of this decomposition are in Appendix A), finding that about 70 percent of the total advertising effect for prescriptions purchased is driven by extensive margin effects. Thus, a substantial proportion of the utilization effect of advertising appears to come from promoting take-up among new users.

\subsubsection{Effects on Drug Adherence}

We extend the above analysis of intensive margin effects by looking specifically at the effects of advertising on drug adherence. Poor adherence to prescribed drug regimens for chronic conditions reduces their effectiveness, leading to worse health outcomes (summarized in DiMatteo, et al., 2002) and greater healthcare costs on the order of $\$ 100$ to $\$ 289$ billion annually. Noncompliance is common with an estimated 50 percent of patients with chronic diseases not following treatment regimens as prescribed (Viswanathan, et al., 2012). While it is difficult, using claims data, to definitively interpret rising drug utilization due to advertising as appropriate use, increasing drug adherence has clearer positive welfare implications because it has been shown to improve health. Adherence is also a channel through which advertising may directly impact consumer prescription drug behaviors independent of physician decisions. Advertising may increase adherence if it serves as a reminder to take medication, makes the chronic condition more salient (especially for asymptomatic diseases such as hyperlipidemia), or increases the perceived benefits of treatment. It may also reduce adherence if it enhances awareness of harmful side effects.

First, we present the results for drug adherence graphically in Figure 7. This figure is analogous to the previous figures showing the trend in drug utilization across high and low elderly share areas, using as the outcome the proportion of non-elderly individuals with "high adherence" (defined as MPR $\geq 80 \%$ ). Similar results for the continuous measure of MPR are in Appendix Figure B.3. Adherence is mechanically very high in the first few quarters of the study period because we start following patients in the quarter of their first observed drug treatment 
and most individuals in these early quarters have just initiated treatment by construction. ${ }^{41}$ This mechanical relationship in the data is uniform across geographic areas, as is visible in Figure 7, and should not impact our results. Additionally, we will show that excluding these early quarters from the analysis has little effect on the results. Once the adherence measure has stabilized in 2005, we find that the proportion of non-elderly with high adherence is nearly identical across high and low elderly share areas, but then immediately diverges in 2006. There is an absolute and relative increase in adherence in high elderly share areas and this effect is persistent.

To estimate the magnitude of this effect we present the corresponding regression results for the reduced form and 2SLS estimates in Panel A of Table 9. We present results separately for the full sample period (2004-2010), excluding the recession years (2004-2007), and excluding the first year when adherence is mechanically high (2005-2007). The results are qualitatively similar across samples. In the full sample, we find that comparing high elderly share areas to low elderly share areas, Part D led to a 0.4 percentage point increase in the proportion of individuals with high adherence (or about a 1 percent increase relative to the 2005 mean of $56 \%$ ). When restricting the sample to $2005-2007$, the estimate increases to 1.2 percentage points. Only the latter estimate is statistically significant at conventional levels. The 2SLS estimates are also positive and largely significant. Given an $8.1 \%$ increase in advertising exposure after Part D, these estimates imply an adherence elasticity with respect to advertising ranging from 0.09 to 0.25 depending on the sample. At the high end, the number of ads viewed would need to increase by 40 percent in order to increase adherence by 10 percent. In the full sample, the elasticity for adherence is roughly one-sixth the size of the elasticity for total utilization. Using the continuous MPR as the outcome variable instead of the proportion with high adherence produces very similar estimates (see Appendix Table B.5).

In our baseline results, we compute the MPR between a person's first and last drug claim. However, inappropriate discontinuation of treatment is also an important dimension of nonadherence. In Panel B of Table 9, we compute an alternative measure of MPR where we assume that the MPR equals zero after the last observed drug claim. ${ }^{42}$ With this measure, MPR reflects

\footnotetext{
${ }^{41}$ For example, in the first quarter, everyone in the sample has filled at least one prescription, so their adherence will be atypically high. In the second quarter, everyone has filled at least one prescription in that quarter or the previous quarter, and so forth. In later quarters, the sample composition becomes more balanced.

${ }^{42}$ This assumption is most appropriate for chronic conditions that require lifetime treatment. Of our five conditions, depression may be an exception to this because treatment guidelines recommend that a patient receives treatment until the symptoms have been alleviated and then continued only for a short time thereafter to prevent relapse, which
} 
both compliance with an ongoing prescription and the rate at which medication is discontinued. The 2SLS results using this alternative measure of MPR (Row 2) are slightly larger in both absolute and relative terms in most samples. This is suggestive that advertising may also reduce the rate of treatment discontinuation.

The changes in adherence represent a combination of behaviors from both existing and new drug users. In particular, the increase in advertising after Part D may have caused more people to initiate drug treatment. These new entrants into the sample may have had different underlying compliance behavior (i.e. higher or lower adherence). To isolate the adherence responses of the existing patients from the new initiators, in Table 9 Panel B (Rows 3 and 4), we replicate the previous table using only the sample of individuals who initiated drug treatments in 2004 or 2005, before the introduction of Part D. When we exclude the new initiators, the results become larger for both measures of MPR. This suggests that the marginal person who initiates treatment because of advertising is on average less compliant. A back-of-the-envelope calculation suggests that those who initiate treatment due to advertising are about half as likely to have high adherence $(\mathrm{MPR} \geq 80 \%)$ relative to existing patients. ${ }^{43}$ There are a few possible reasons for this. The marginal person might have a less severe condition or advertising may attract people who are less attached to treatment (e.g. someone impulsively trying something new they saw on television only to quickly discontinue its use). Thus, while increasing adherence among existing users may be welfare enhancing, the welfare effects of new initiation due to advertising are less clear. Advertising appears to be capturing some individuals for whom treatment is marginally less appropriate and less beneficial, or new initiators may simply comply less with prescribed treatments. Thus, some of this additional drug use could represent wasteful spending since initiating chronic treatments without adhering to them does not improve health.

\subsection{Spillover Effects to Non-Advertised Drugs}

Finally, we analyze whether there were spillover effects of advertising on non-advertised drugs to test for market expansion effects of advertising. While a brand's advertising may also

could be as little as 4 months of treatment (Donahue et al., 2004). Our baseline MPR measure is conservative as it does not assume that lifetime treatment is clinically necessary.

${ }^{43}$ The total effect of advertising on adherence is 0.017 , which is a weighted average of the effect for new initiators and existing patients. The adherence effect for existing patients is 0.022 . The probability of drug take-up increased by 0.001 after Part D in high elderly share areas from a baseline of 0.06 . Using this estimate, combined with the adherence effects, we estimate that the proportion of non-elderly individuals with high adherence after Part D is 0.632 for existing patients and 0.319 for new initiators. 
have spillovers on the use of other advertised brands, we can identify only the net effect on the overall demand for advertised drugs within a condition. Thus, we focus on identifying spillovers on non-advertised drugs, which is one component of the overall market expansion effect. Positive spillover effects could occur if a person viewing an ad for a brand name drug requests this drug from her doctor, but the doctor then prescribes another therapeutically similar drug. Insurance formularies that cover only certain drugs or offer preferential cost-sharing for certain drugs could also induce spillovers. We test for spillover effects by re-estimating Equation 3, replacing the outcome variable with the total prescriptions purchased for non-advertised drugs belonging to the same therapeutic drug classes as the 50 advertised chronic drugs.

We show the results graphically in Figure 8 comparing the trends in average prescriptions purchased across high and low elderly share markets for advertised drugs (repeated from Figure 3), non-advertised drugs, and both types of drugs combined. For non-advertised drugs, we see nearly identical trends across markets prior to Part D and then both an absolute and relative increase in utilization in high elderly share markets immediately after the introduction of Part D. This provides strong evidence of a market expansion effect. The secular increase in utilization, which differs from the declining trend we see for advertised drugs, reflects the fact that nonadvertised drugs are typically generics or off-patent brands and that there is substitution from the brand-name drugs to generics after brands lose patent protection. We also observe a large differential effect of Part D on total utilization. Thus, the effect cannot be driven purely by substitution from non-advertised drugs to advertised drugs. The regression analogs in Table 10 show that these effects are all positive and statistically significant. Consistent with the previous advertising literature, we find large positive spillovers from advertising. This has welfare implications for both consumers and firms. From the consumer perspective, the spillovers may be welfare enhancing as this suggests at least some role for informative, rather than marketstealing advertising. In contrast, had we found a complete shift from non-advertised to advertised drugs, this would have represented little welfare gain since advertised drugs may not be significantly superior to non-advertised drugs. 


\section{Discussion}

Our results demonstrate that DTCA has large causal effects on drug utilization and drug adherence. We study the effects of a market-wide shock to advertising, which allows us to identify the net impact on drug use. ${ }^{44}$ Other work in the literature focuses on how advertising affects an individual firm's own revenue (e.g. Sinkinson and Starc, 2015, Shapiro, 2015). Our interest is in how public policy influences market-wide incentives for DTCA, and in the resulting implications for patients. To inform the debate over whether DTCA should be encouraged, limited, or banned, the aggregate effect of expanding advertising for all drugs is the relevant policy parameter. Other policies that stimulate DTCA might have different local average treatment effects (Imbens and Angrist, 1994). However, our policy experiment bears directly on policies expanding public insurance. It may also correspond closely to other broad-based polices that affect a large fraction of drugs (especially drugs for our five chronic conditions).

Our estimates can also be used to consider the contribution of DTCA to the overall growth in drug spending since the FDA relaxed its advertising restrictions in 1997. To recover this parameter, we begin by estimating the advertising elasticity for total drug spending (including spillover effects on non-advertised drugs) in Appendix Table B.6. Our results imply that a 10 percent increase in advertising views increases total drug spending by about 4 percent (using the more conservative binary instrument). We deflate this estimate by a factor of 2.3 to account for the relationship between advertising expenditures and advertising views (Sethuraman et al., 2011), since we only know time series growth in advertising expenditures. Based on this estimate, we predict that drug spending would increase by $59 \%$ in response to the increase in national DTCA expenditures from 1997-2010. Comparing this to the actual increase in national drug spending (193\%), DTCA accounts for about $31 \%$ of the recent growth in drug spending. While one must exercise caution in extrapolating our estimates to the national historical trend, our results are suggestive that DTCA is a significant, though not primary, contributor to the rapid rise in drug spending in the U.S.

Evaluating the welfare consequences of the rise in drug utilization and spending, requires an understanding of the benefits and value of DTCA. We find that a large share of the utilization

\footnotetext{
${ }^{44}$ Since Part D affected advertising incentives for all drugs, it does not serve as an appropriate instrument to test for market stealing between one advertised brand name drug and another.
} 
response to advertising is driven by take-up of treatment. Given that the five conditions we study are generally considered to be under-treated and under-diagnosed (e.g. Hirschfeld, et al., 1997; Majumdar et al., 1999), increased take-up is likely to lead to improved health, representing a welfare gain for consumers. However, we find that individuals who initiate therapy due to advertising have lower rates of treatment compliance, which could mitigate some of these health gains. For patients who are less attached to treatment regimens or for whom treatment is marginally less appropriate, increased spending may lead to little health improvement. Furthermore, if advertising serves primarily to persuade, rather than to inform, we may observe distortions in use towards the newest, most expensive drugs, irrespective of their quality. Our evidence on spillover effects suggests that a significant share of the increase in utilization comes from non-advertised drugs which tend to be lower cost off-patent and generic drugs. We also find effects of DTCA on improving drug adherence. This has clearer positive welfare implications. Although, a small proportion of the adherence effect is mitigated by a composition change towards new initiators who appear to be less compliant. Our estimates provide a rich picture of the utilization responses to DTCA by examining numerous mechanisms explaining the overall increase and provide an important step in understanding advertising's welfare effects. Ultimately, an analysis of the health benefits as well as other perceived utility gains from the additional treatments induced by DTCA would be needed to characterize the full welfare effects. This goes beyond the scope of the current analysis, given the limited measures of health available in our claims data, but represents a potentially important area for future research.

\section{Conclusion}

This paper provides one of the first natural experiment studies of the impact of direct-toconsumer advertising on drug utilization and sheds light on the causal mechanisms for the advertising effect. We exploit variation in advertising driven by the introduction of Medicare Part D by comparing changes in drug utilization for the non-elderly before and after Part D in markets with high versus low elderly share.

The results of this study show that advertising exposure for the non-elderly increased differentially in high elderly share markets immediately following the implementation of Part D. This pattern is mimicked by our drug utilization outcomes along both the extensive and intensive 
margins. While drug utilization pre-trends tracked each other closely prior to Part $\mathrm{D}$, we find a differential increase for the non-elderly following Part D. Decomposing the total utilization effect, we find that the effects are driven both by increased take-up and drug adherence. Increased take-up accounts for about $70 \%$ of the total utilization effect.

The utilization results are robust to trends and alternative specifications of the instrument. Also, we find that the results are not sensitive to changes in the composition of the sample due to firm and employee churn in the claims data. We find no evidence to suggest that the utilization patterns are driven by changes in prices, physician prescribing behavior, or detailing that is differentially occurring in high elderly share areas. We also find large spillover effects of advertising on utilization of non-advertised drugs, leading to overall market expansion effects.

Overall, we find substantial responsiveness of prescription drug demand to a non-price factor. Based on the review in Goldman, Joyce and Zheng (2007), estimates of the price elasticity of demand for prescription drugs range from -0.2 to -0.6. Using this range of estimates, our results imply that a 10 percent increase in advertising exposure produces the same increase in prescription drug utilization as a 9 to 27 percent reduction in out-of-pocket price. ${ }^{45}$ The substantial spillover effects of Part D on the non-elderly population may also warrant consideration by policymakers. These unintended behavioral responses to the policy by individuals outside of the Medicare program may have considerable welfare consequences.

\footnotetext{
${ }^{45}$ Using our estimated elasticity of demand with respect to advertising of 0.54 , we compute the corresponding price elasticity equivalent to a $10 \%$ change in advertising exposure as: $(0.54 / .2) * 10=27$ or $(0.54 / .6) * 10=9$.
} 


\section{References}

Alpert, A. 2015. The anticipatory effects of Medicare Part D on drug utilization. Mimeo.

Andrade, S., et al. 2006. Methods for evaluation of medication adherence and persistence using automated databases. Pharmacoepidemiology and Drug Safety. 15(8):565-574.

Avery, R., Eisenberg, M. and K. Simon. 2012. The impact of direct-to-consumer television and magazine advertising on antidepressant use. Journal of Health Economics. 31:705-718.

Blume-Kohout, M. and N. Sood. 2013. Market size and innovation: Effects of Medicare Part D on pharmaceutical research and development. Journal of Public Economics. 97:327-336.

Bradford, W., et al. 2006. How direct-to-consumer television advertising for osteoarthritis drugs affect physicians' prescribing behavior. Health Affairs. 25(5):1371-1377.

Centers for Medicare and Medicaid Services. 2012. Chronic conditions among Medicare beneficiaries.

Dave, D. 2013. Effects of pharmaceutical promotion: A review and assessment. NBER Working Paper 18830.

Dave, D. and H. Saffer. 2012. Impact of direct-to-consumer advertising on pharmaceutical prices and demand. Southern Economic Journal. 79(1): 97-126.

DiMatteo, M., et al. 2002. Patient adherence and medical treatment outcomes: a meta-analysis. Medical Care. 40(9): 794-811.

Donohue, J., Berndt, E., Rosenthal, M., et al., 2004. Effects of pharmaceutical promotion on adherence to the treatment guidelines for depression. Medical Care. 42(12): 1176-1185.

Duggan, M. and Scott Morton, F. 2010. The impact of Medicare Part D on pharmaceutical prices and utilization. American Economic Review. 100(1):590-607.

Goldman, D., Joyce, G., and Zheng, Y. 2007. Prescription drug cost sharing: Associations with medication and medical utilization and spending and health. Journal of the American Medical Association. 298(1):61-69.

Goldman, D., et al. 2004. Pharmacy benefits and the use of drugs by the chronically ill. Journal of the American Medical Association. 291(19): 2344-2350.

Hess, L, et al. 2006. Measurement of adherence in pharmacy administrative databases: A proposal for standard definitions and preferred measures. Annals of Pharmacotherapy. 40:1280-1288. 
Hirschfeld, R, et al. 1997. The National Depressive and Manic-Depressive Association consensus statement on the undertreatment of depression. Journal of the American Medical Association. 277(4):333-340.

Hollon, M. 2005. Direct-to-consumer advertising: A haphazard approach to health promotion. Journal of the American Medical Association. 293(16):2030-2033.

Holmer, A. 2002. Direct-to-consumer advertising - strengthening our health care system. New England Journal of Medicine. 346(7):526-528.

Iizuka, T. and G. Jin. 2005. The effect of prescription drug advertising on doctor visits. Journal of Economics and Management Strategy. 14(3): 701-727.

Imbens, G. and J. Angrist. 1994. Identification and Estimation of Local Average Treatment Effects. Econometrica. 62(2):467-475.

Joyce, G., Goldman, D., Karaca-Mandic, P., and Y. Zheng. 2007. Pharmacy benefit caps and the chronically ill. Health Affairs. 26(5): 1333-1344.

Kalyanaram, G., 2009. The endogenous modeling of the effect of direct-to-consumer advertising in prescription drugs. International Journal of Pharmaceutical and Healthcare Marketing. 3(2):137-148.

Kanazawa, M. and J. Funk. 2001. Racial discrimination in professional basketball: Evidence from Nielsen ratings. Economic Inquiry. 39(4): 599-608.

Kantar Media. 2011. Pharmaceutical Marketing. Ad Age Insights White Paper, October 17, 2011.

Kearney, M. and P. Levine. 2014. Media influences on social outcomes: The impact of MTV's 16 and Pregnant on teen childbearing. NBER Working Paper 19795.

Ketcham, J. and K. Simon. 2008. Medicare Part D's effects on elderly drug costs and utilization. American Journal of Managed Care. 11:SP14-22.

Kravitz, R., et al. 2005. Influence of patients' requests for direct-to-consumer advertised antidepressants: A randomized controlled trial," Journal of the American Medical Association. 293(16):1995-2002.

Lakdawalla, D., Sood, N., and Q. Gu. 2013. Pharmaceutical advertising and Medicare Part D. Journal of Health Economics. 32:1356-1367.

Lakdawalla, D., and W. Yin. 2015. Insurers' negotiating leverage and the external effects of Medicare Part D. Review of Economics and Statistics. 97(2):314-331.

Lichtenberg, F. and Sun, S. 2007. The impact of Medicare Part D on prescription drug use by the elderly. Health Affairs. 26(6):1735-1744. 
Majumdar, S., Gurwitz, J., and S. Soumerai. 1999. Undertreatment of hyperlipidemia in the secondary prevention of coronary artery disease. Journal of General Internal Medicine. 14(12):711-717.

Nielsen. 2014. The total audience report. December Issue.

Peterson, A., et al. 2007. A checklist for medication compliance and persistence studies using retrospective databases. Value in Health. 10:3-12.

Rosenthal, M., et al. 2003. Demand effects of recent changes in prescription drug promotions. Frontiers in health policy research. 6:1-26.

Saffer, H., Wakefield, M. and Y. Terry-McElrath. 2007. The effect of nicotine replacement therapy advertising on youth smoking. NBER Working Paper 12964.

Sethuraman, R., Tellis, G., and R. Briesch. 2011. How well does advertising work? Generalizations from meta-Analysis of brand advertising elasticities. Journal of Marketing Research. 48(3):457-471.

Shapiro, B. 2015. Positive spillovers and free riding in advertising of prescription pharmaceuticals: The case of antidepressants. Mimeo.

Sinkinson, M. and A. Starc. 2015. Ask your doctor? Direct-to-consumer advertising of pharmaceuticals. NBER Working Paper 21045.

Stock, J., Wright, J., and M. Yogo. 2002. A survey of weak instruments and weak identification in GMM. Journal of Business and Economic Statistics. 20(4):518-529.

Viswanathan M, et al. 2012. Interventions to improve adherence to self-administered medications for chronic diseases in the United States: A systematic review. Annals of Internal Medicine. 157:785-795.

Wosinska, M. 2002. Just what the patient ordered? Direct-to-consumer advertising and the demand for pharmaceutical products. Harvard Business School Marketing Research Papers No. 02-04.

Wosinska, M. 2005. Direct-to-consumer advertising and drug therapy compliance. Journal of Marketing Research. 42(3): 323-332.

Yin, W. et al. 2008. The effect of the Medicare Part D prescription benefit on drug utilization and expenditures. Annals of Internal Medicine. 148(3):169-177. 
Figure 1 -Direct-to-Consumer Advertising and Prescription Drug Spending, 1960-2010

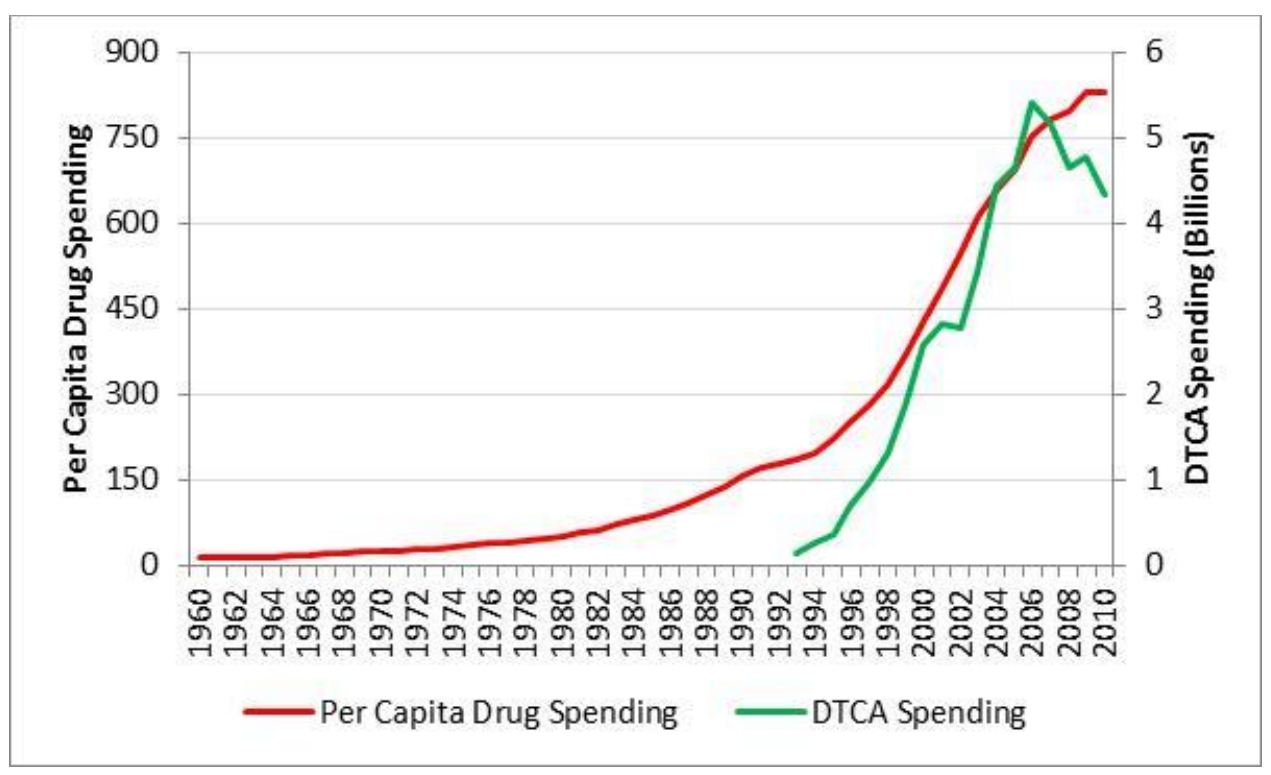

Sources: Dave (2013), National Health Expenditure Accounts (2015). The data are presented in nominal values. 


\section{Figure 2 - Annual Views per Person of TV Ads for Top 200 Brand Name Drugs, for Non-Elderly}

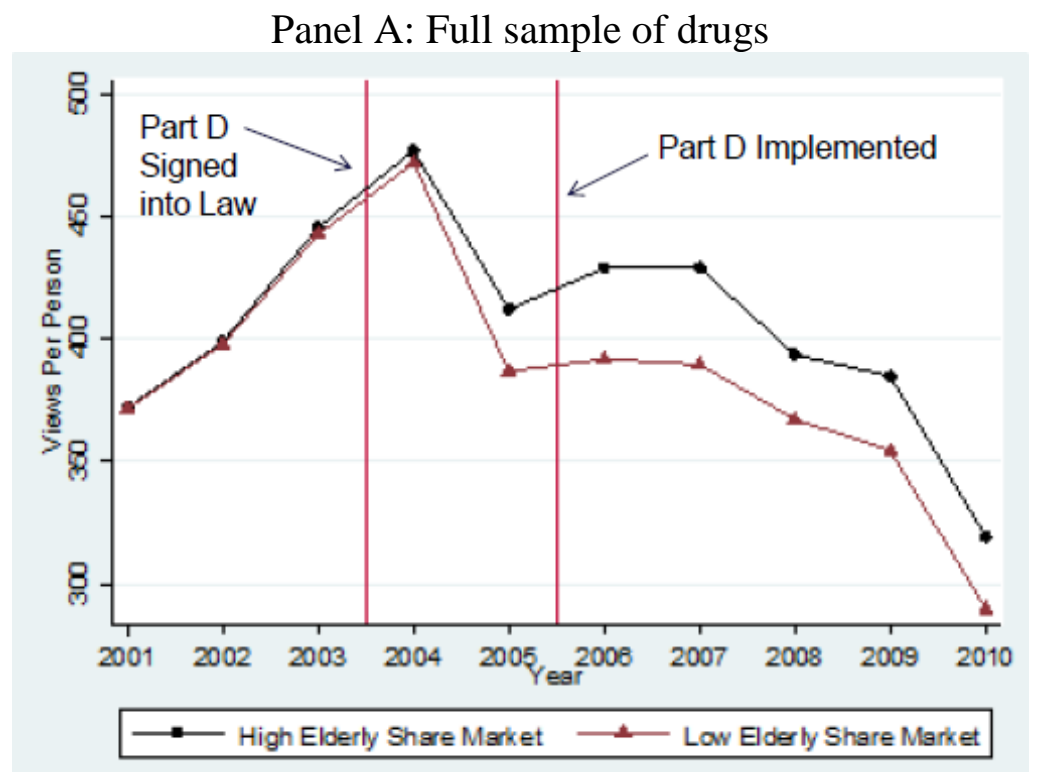

Panel B: Excluding drugs that went off-patent from 2001-2010

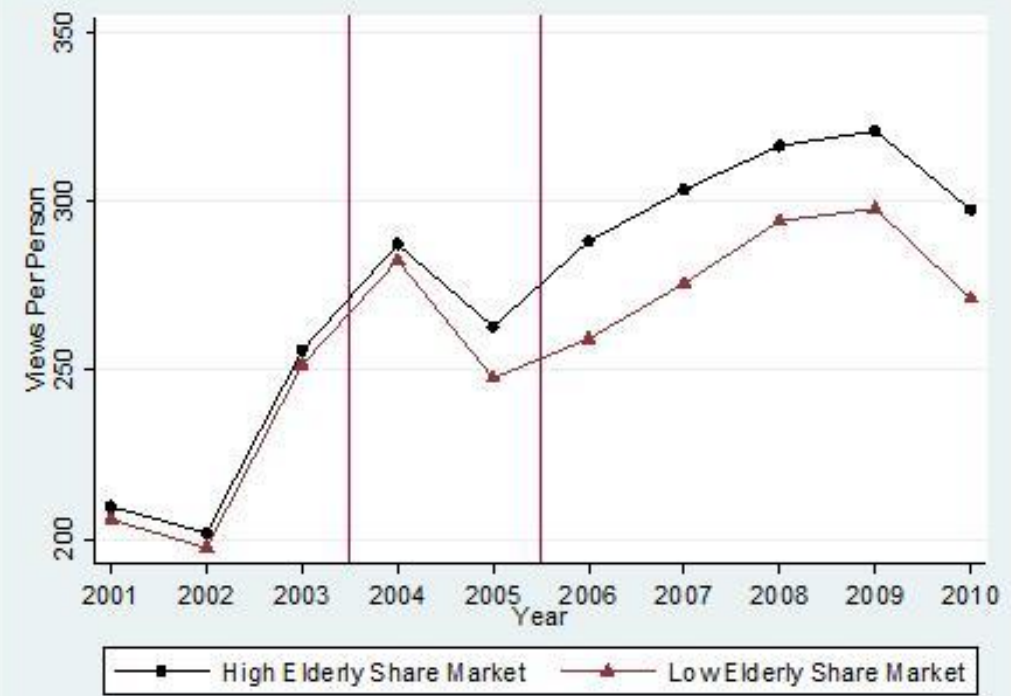

Notes: Sample means from Nielsen Ad*Views in above median elderly share markets relative to below median elderly share markets. The vertical lines represent the dates when Part D was signed into law (December 2003) and was implemented (January 2006). In Panel A, means are plotted for a balanced panel of the top 200 advertised brand-name drugs. There is a secular downward trend in overall views per person due to patent expirations of several of these drugs over this time period (in particular, four of the top 200 drugs went off patent around 2006: Pravachol, Wellbutrin XL, Zocor, and Zoloft). The downward trend in views matches the pattern in national advertising expenditures shown in Figure 1. In Panel B, we exclude all drugs that went off-patent during the study period. 


\section{Figure 3 - Quarterly Views per Person of TV Ads and Mean Utilization of Chronic Drugs, for Non-Elderly}

\section{Panel A: Views Per Person for Chronic Drug Ads}

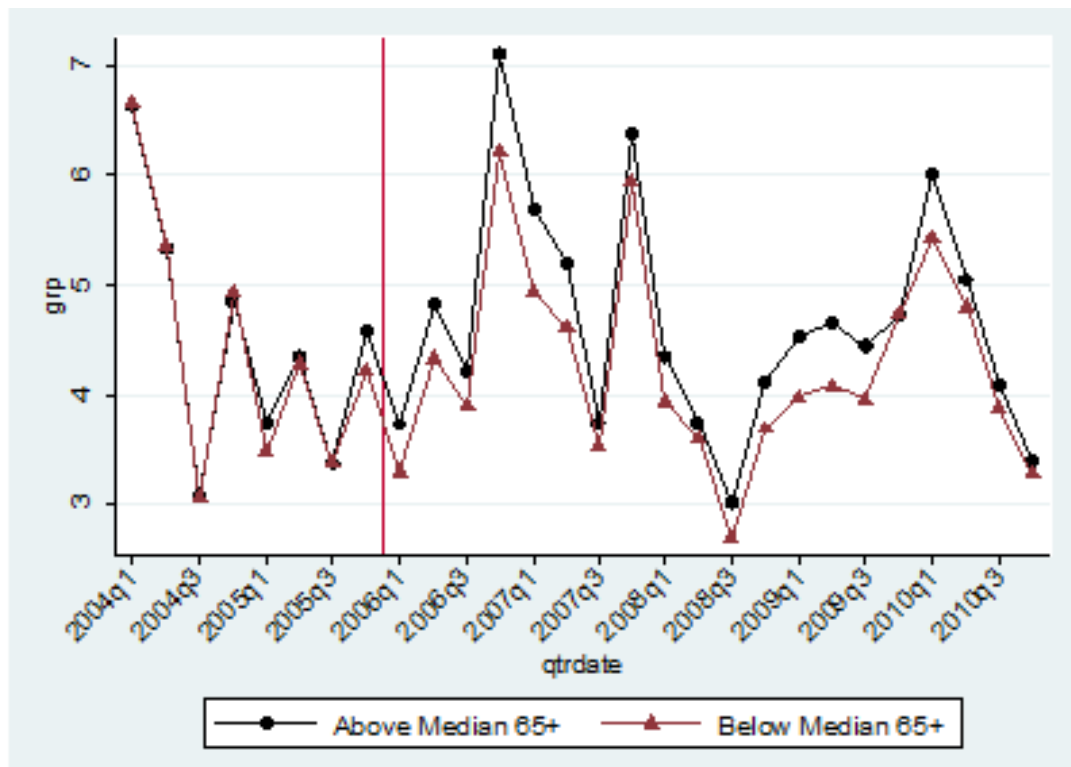

Panel B: Average Number of Prescriptions Purchased for Chronic Drugs

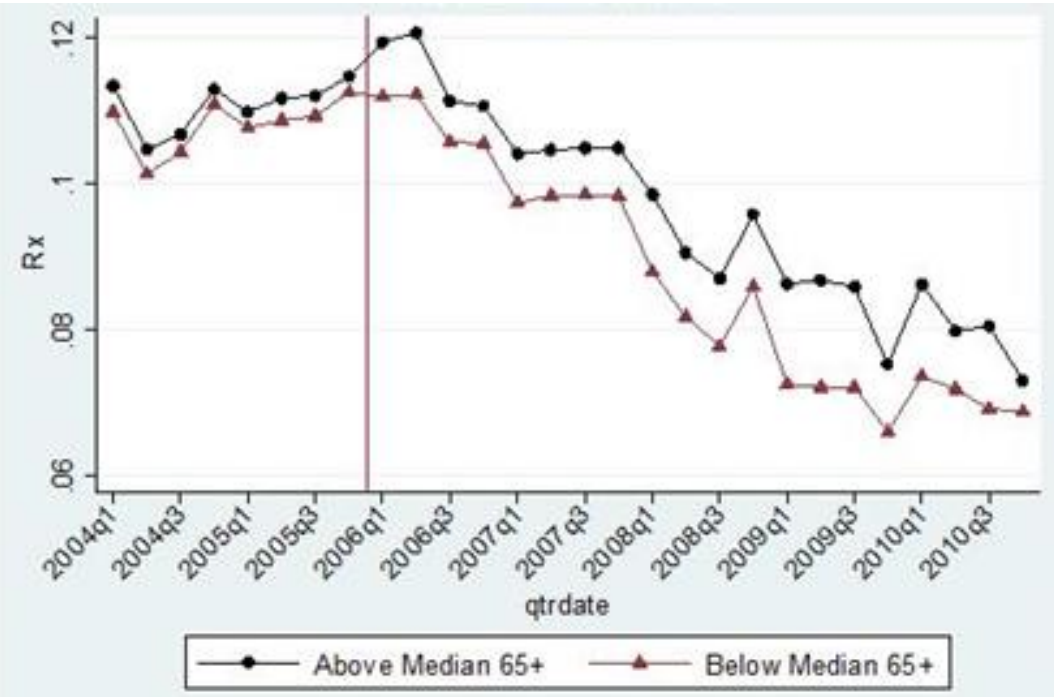

Notes: Sample means from Nielsen Ad*Views (views per capita for non-elderly) and claims (mean number of total prescriptions purchased for non-elderly) in above median elderly share markets relative to below median elderly share markets. Includes the 50 drugs that advertised during the study period for 5 chronic conditions: depressions, diabetes, hyperlipidemia, hypertension, and osteoporosis. The vertical line represents the implementation date of Medicare Part D. 
Figure 4 - Placebo Test: Annual Views per Person of TV Ads for Contraceptive Drugs, for Non-Elderly

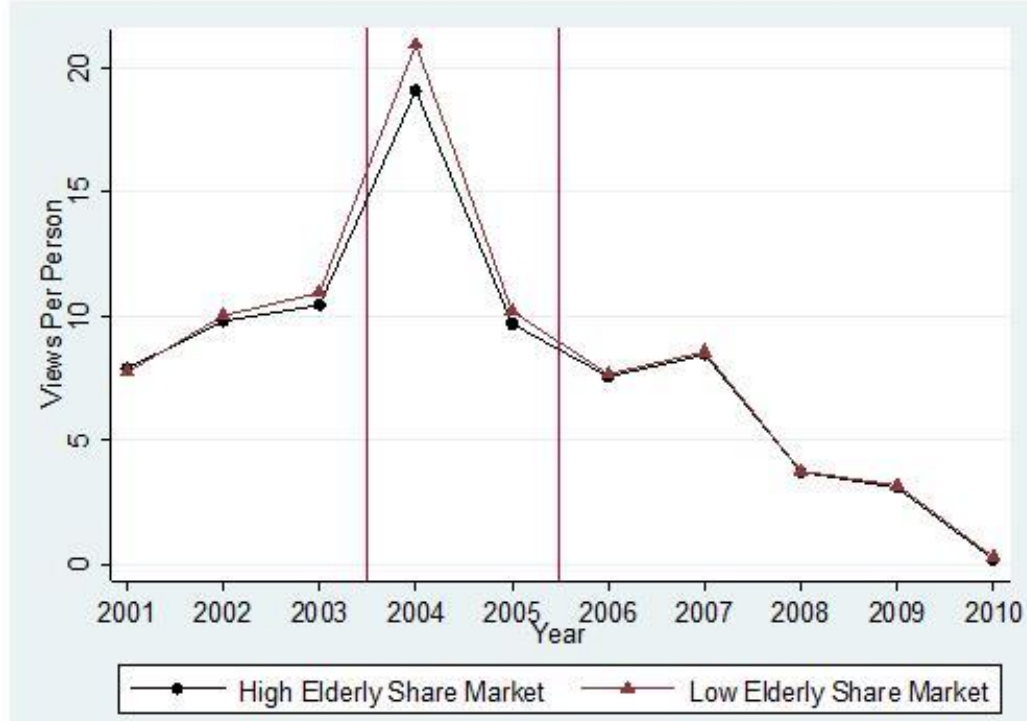

Notes: Sample means for contraceptive drugs from Nielsen Ad*Views in above median elderly share markets relative to below median elderly share markets. The vertical lines represent the dates when Part $\mathrm{D}$ was signed into law (December 2003) and was implemented (January 2006). 


\section{Figure 5 - Mean Out-of-Pocket Price for Chronic Drugs, for Non-Elderly}

\section{Panel A: All NDCs - Chronic Drugs}

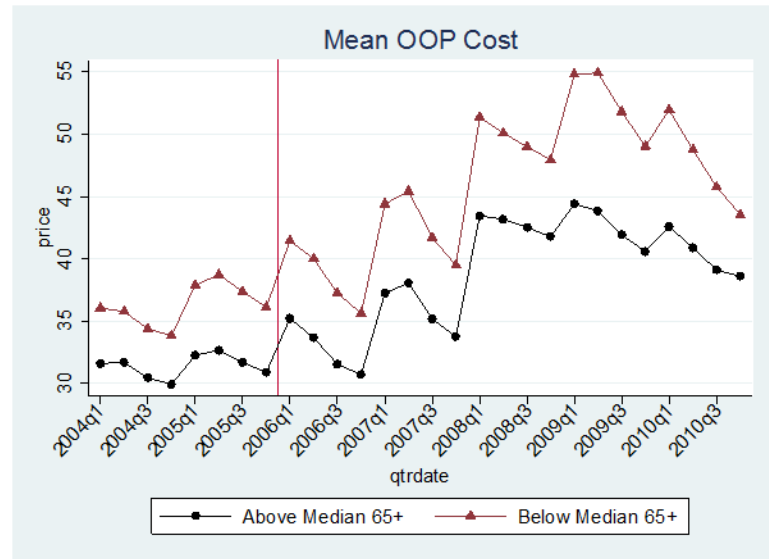

Panel B: Balanced Panel of NDCs (2004-2007) - Chronic Drugs

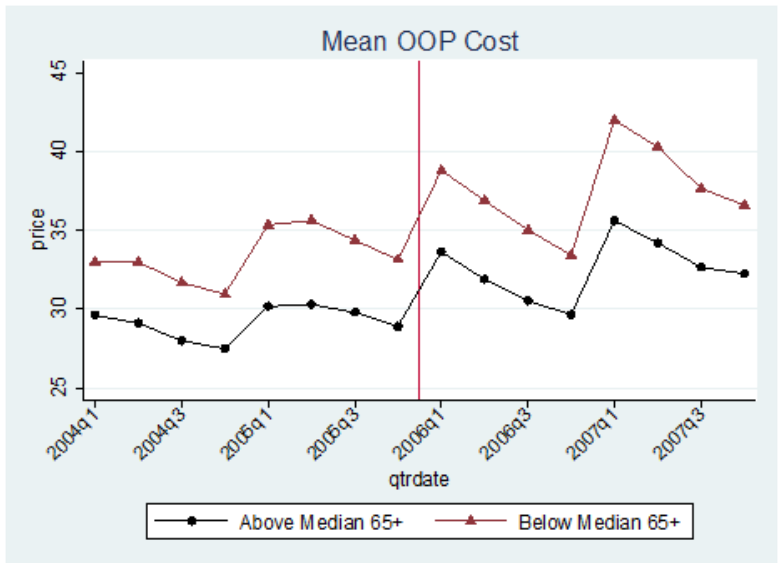

Notes: Sample means from claims (mean out-of-pocket price, ages 40-60) in above median elderly share markets relative to below median elderly share markets. Panel A includes all NDCs (drug products) associated with the 50 chronic drugs that advertised during the study period. Panel B repeats the exercise in Panel A using a balanced panel of NDCs from 2004-2007 (i.e. each NDC has a non-missing observation in each quarter). We exclude one observation that is an extreme outlier ( $\$ 333,493$ for Actos in Q1:2009 in low elderly share areas) and likely to be reporting error. The vertical line represents the implementation date of Medicare Part D. 
Figure 6 - Mean Utilization for Advertised Drug Classes vs. Non-Advertised Drug Classes, for Non-Elderly

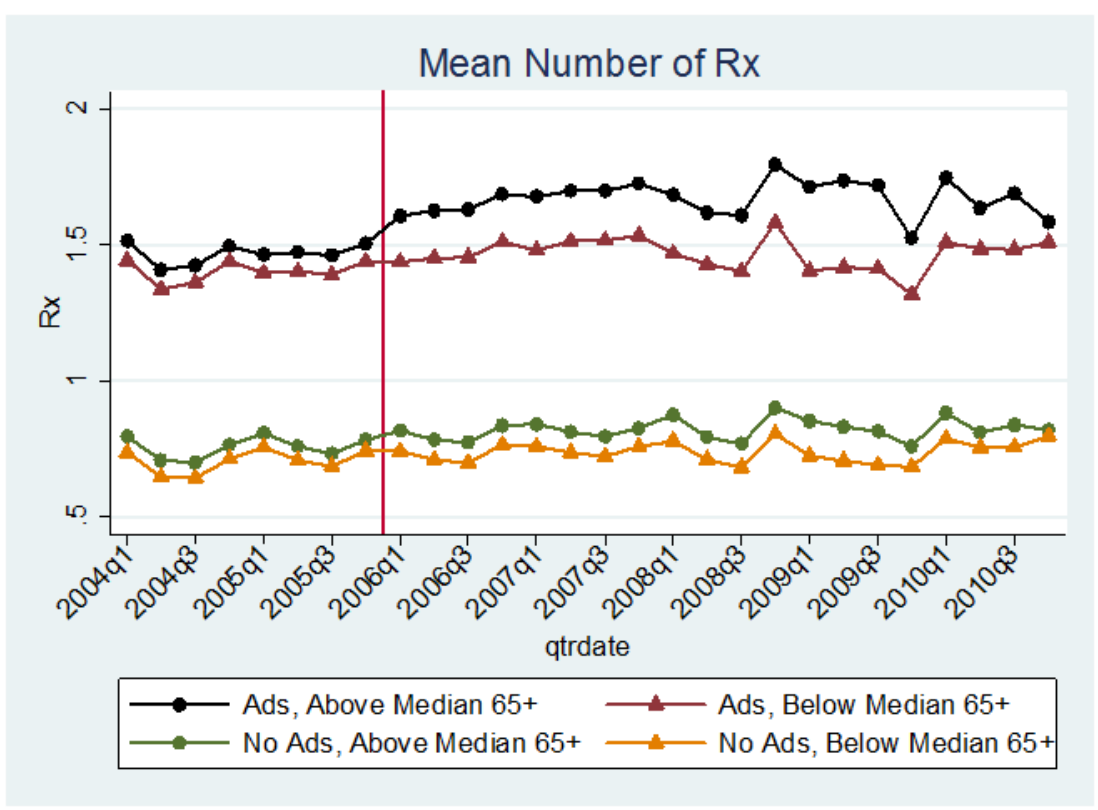

Notes: Sample means from claims (mean number of total prescriptions purchased, ages 40-60) in above median elderly share markets relative to below median elderly share markets. The top two lines (black and red) are for the top 10 advertised drug classes and the bottom two lines (green and orange) are for the top 10 non-advertised drug classes (see Appendix Table B.3 for full list of drug classes included). The vertical line represents the implementation date of Medicare Part D. 


\section{Figure 7 -Proportion with High Adherence of Chronic Drugs, for Non-Elderly}

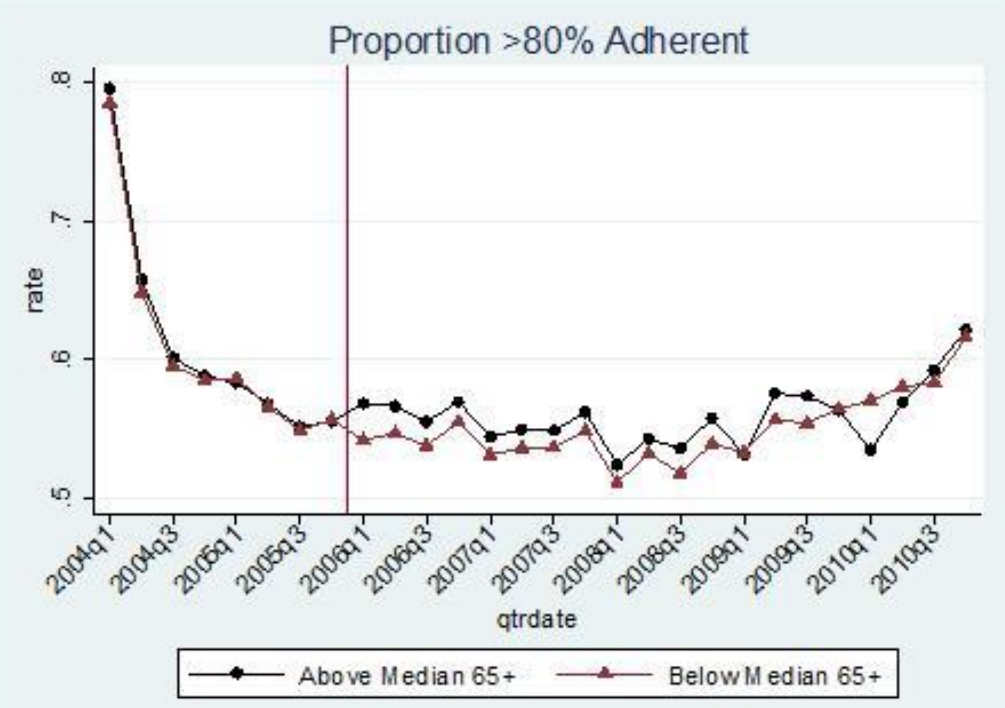

Notes: Sample means from claims (proportion of individuals with MPR $\geq 80 \%$, ages 40-60) in above median elderly share markets relative to below median elderly share markets. Includes the 50 drugs that advertised during the study period and the drugs that did not advertise for 5 chronic conditions: depression, diabetes, hyperlipidemia, hypertension, and osteoporosis. The vertical line represents the implementation date of Medicare Part D. 
Figure 8 - Quarterly Mean Utilization of Chronic Drugs: Spillover Effects

Panel A: Advertised Chronic Drugs

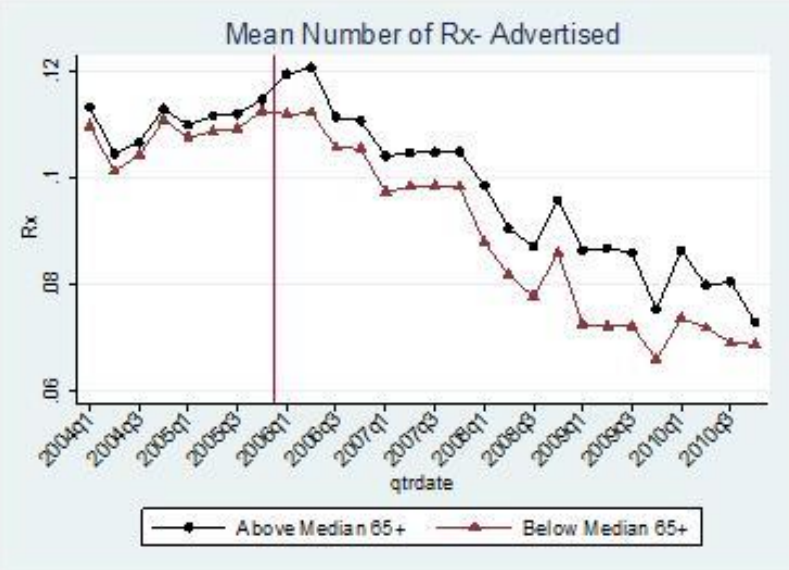

Panel B: Non-Advertised Chronic Drugs

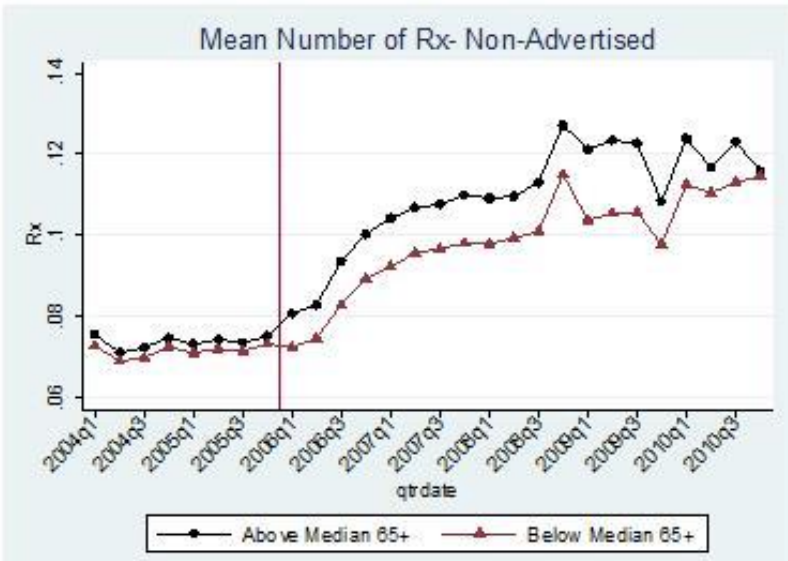

Panel C: Total Chronic Drugs

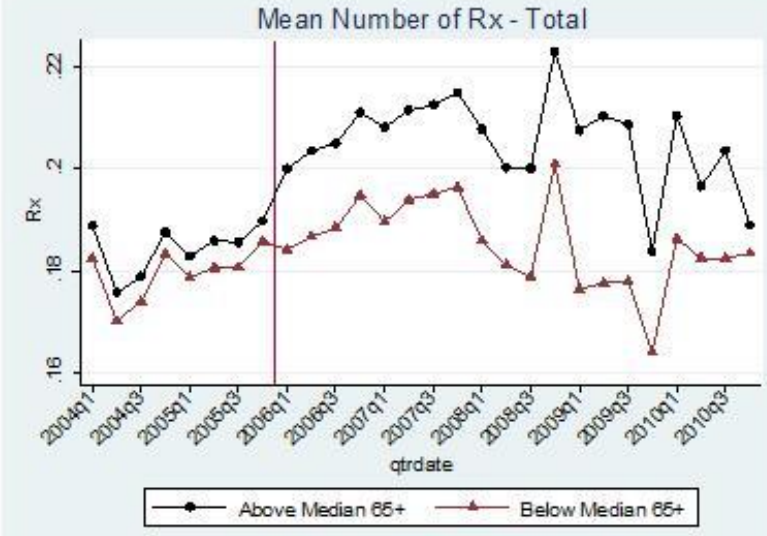

Notes: Sample means from claims (mean number of total prescriptions purchased, ages 40-60) in above median elderly share markets relative to below median elderly share markets. Panel A includes the 50 chronic drugs that advertised during the study period (repeated from Figure 3), Panel B includes drugs in the same classes that did not advertise, Panel $\mathrm{C}$ includes both advertised and non-advertised drugs. The vertical line represents the implementation date of Medicare Part D. 
Table 1 - Heterogeneity in Elderly Share Across Local TV Markets

\begin{tabular}{lcccc}
\hline \hline & & $\begin{array}{c}\text { Pop 65+ } \\
\text { (Cens us }\end{array}$ & \begin{tabular}{c} 
Total Pop \\
(Census \\
\multicolumn{1}{c}{ TV Market (DMA) }
\end{tabular} & $\begin{array}{c}\text { TV Market } \\
\text { Ranking } \\
\text { (Size) }\end{array}$ \\
\hline Top 8 High Elderly Share Markets & & & & \\
FT. MYERS-NAPLES & & & & \\
WEST PALM BEACH-FT. PIERCE & 0.257 & 234,535 & 912,887 & 62 \\
TAMPA-ST. PETE (SARASOTA) & 0.238 & 380,814 & $1,598,528$ & 38 \\
WILKES BARRE-SCRANTON-HZTN & 0.213 & 787,553 & $3,702,269$ & 14 \\
PITTSBURGH & 0.175 & 259,761 & $1,481,798$ & 54 \\
ORLANDO-DAYTONA BCH-MELBRN & 0.173 & 503,077 & $2,901,329$ & 23 \\
PADUCAH-CAPE GIRARD-HARSBG & 0.167 & 488,991 & $2,926,227$ & 18 \\
SPRINGFIELD, MO & 0.158 & 156,329 & 987,215 & 81 \\
& & & & 75 \\
Top 8 Low Elderly Share Markets & & & & \\
\hline HOUSTON & & & & \\
SALT LAKE CITY & 0.082 & 410,910 & $5,020,575$ & 10 \\
AUSTIN & 0.085 & 204,008 & $2,387,354$ & 33 \\
ATLANTA & 0.085 & 116,640 & $1,371,385$ & 40 \\
DALLAS-FT. WORTH & 0.085 & 437,654 & $5,149,717$ & 9 \\
DENVER & 0.087 & 503,232 & $5,761,057$ & 5 \\
WASHINGTON, DC (HAGRSTWN) & 0.093 & 320,372 & $3,451,529$ & 17 \\
LOS ANGELES & 0.098 & 501,141 & $5,232,970$ & 8 \\
\hline
\end{tabular}

Notes: TV markets are defined by Nielsen Designated Market Areas (DMAs). Elderly share and population counts are from the 2000 Census. 
Table 2 - Sample Means of Nielsen Advertising Variables by Elderly Share

\begin{tabular}{lcc|cc|cc}
\hline \hline & \multicolumn{2}{c|}{2005} & \multicolumn{2}{c|}{2007} & \multicolumn{2}{c}{ 2005-07 Change } \\
\cline { 2 - 7 } & \multicolumn{2}{c}{ Low Elderly High Elderly } & \multicolumn{2}{c}{ Low Elderly High Elderly } & \multicolumn{2}{c}{ Low Elderly } \\
Variable (Mean) & Share & Share & Share & Share & Share & Share \\
\hline Proportion 65+ (2000) & 0.110 & 0.146 & 0.110 & 0.146 & - & - \\
Population 65+ (2000) & 333,864 & 256,288 & 333,864 & 256,288 & - & - \\
Total Population (2000) & $3,070,123$ & $1,748,112$ & $3,070,123$ & $1,748,112$ & - & - \\
& & & & & & \\
Views per Person (ages 2-64) & 387 & 413 & 390 & 429 & 3 & 17 \\
Views per Person (ages 65+) & 1,184 & 1,150 & 1,214 & 1,233 & 30 & 82 \\
& & & & & & 50 \\
Year x Market observations & 50 & 50 & 50 & 50 & 50 & 50 \\
\hline
\end{tabular}

Notes: Means are computed across DMAs by year for the top 200 advertised brand-name drugs. Views per Person (rating points) are from the Nielsen data. Elderly share and population counts are from the 2000 Census. 


\section{Table 3 - Baseline Regressions for Total Utilization of Chronic Drugs, for Non-Elderly}

\begin{tabular}{|c|c|c|c|}
\hline \multirow[b]{2}{*}{ Dependent Variable: } & First Stage & Reduced Form & \multirow{2}{*}{$\begin{array}{c}\text { 2SLS } \\
\text { \# of } \\
\text { Prescriptions }\end{array}$} \\
\hline & $\begin{array}{c}\text { Views per Person } \\
\text { (Non-Elderly) }\end{array}$ & $\begin{array}{c}\text { \# of } \\
\text { Prescriptions }\end{array}$ & \\
\hline & (1) & (2) & (3) \\
\hline \multicolumn{4}{|l|}{ A. Instrument $=$ Share $65+*$ Post } \\
\hline Share65+*Post & $\begin{array}{c}6.358^{* * * *} \\
(1.116)\end{array}$ & $\begin{array}{c}0.107 * * * \\
(0.023)\end{array}$ & \\
\hline Views per Person (Non-Elderly) & & & $\begin{array}{c}0.017 * * * \\
(0.004)\end{array}$ \\
\hline F-statistic & 32.69 & & \\
\hline \multicolumn{4}{|c|}{ B. Instrument $=$ High Elderly Share ${ }^{*}$ Post } \\
\hline High Elderly Share*Post & $\begin{array}{c}0.348 * * * \\
(0.063)\end{array}$ & $\begin{array}{c}0.005 * * * \\
(0.001)\end{array}$ & \\
\hline Views per Person (Non-Elderly) & & & $\begin{array}{c}0.014 * * * \\
(0.005)\end{array}$ \\
\hline F-statistic & 30.86 & & \\
\hline Mean of Dep. Var. (pre- Part D) & 4.28 & 0.11 & 0.11 \\
\hline Zipcode x Condition x Quarter Obs & 107,345 & 107,345 & 107,345 \\
\hline
\end{tabular}

Notes: $* * * p<0.01, * * \mathrm{p}<0.05, * \mathrm{p}<0.1$. Clustered standard errors at the 3 -digit ZIP code level; all specifications include quarter fixed effects, 3-digit ZIP code fixed effects, condition fixed effects. Includes the 50 drugs that advertised during the study period for 5 chronic conditions: depression, diabetes, hyperlipidemia, hypertension, and osteoporosis. Data is from 2004-2010. 


\section{Table 4 - Timing of the Impact on Total Utilization of Chronic Drugs, for Non-Elderly}

\begin{tabular}{|c|c|c|c|}
\hline Dependent Variable: & $\begin{array}{c}\text { \# of Prescriptions } \\
\text { (1) }\end{array}$ & & $\begin{array}{c}\text { \# of Prescriptions } \\
\text { (2) }\end{array}$ \\
\hline Share65+*2004:Q1 & $\begin{array}{c}0.051 \\
(0.051)\end{array}$ & HighShare * 2004:Q1 & $\begin{array}{c}0.002 \\
(0.003)\end{array}$ \\
\hline Share65+*2004:Q2 & $\begin{array}{c}0.066 \\
(0.043)\end{array}$ & HighShare* 2004:Q2 & $\begin{array}{c}0.002 \\
(0.002)\end{array}$ \\
\hline Share65+*2004:Q3 & $\begin{array}{c}0.046 \\
(0.043)\end{array}$ & HighShare * 2004:Q3 & $\begin{array}{c}0.001 \\
(0.002)\end{array}$ \\
\hline Share65+*2004:Q4 & $\begin{array}{c}0.035 \\
(0.043)\end{array}$ & HighShare * 2004:Q4 & $\begin{array}{c}0.001 \\
(0.002)\end{array}$ \\
\hline Share65+*2005:Q1 & $\begin{array}{c}-0.022 * * \\
(0.010)\end{array}$ & HighShare * 2005:Q1 & $\begin{array}{c}0.000 \\
(0.001)\end{array}$ \\
\hline Share65+*2005:Q2 & $\begin{array}{c}0.002 \\
(0.008)\end{array}$ & HighShare* 2005:Q2 & $\begin{array}{c}0.001 \\
(0.001)\end{array}$ \\
\hline Share65+*2005:Q3 & $\begin{array}{c}0.000 \\
(0.006)\end{array}$ & HighShare * 2005:Q3 & $\begin{array}{l}0.001 \\
0.000\end{array}$ \\
\hline Share65+* 2006:Q1 & $\begin{array}{c}0.133 * * * \\
(0.030)\end{array}$ & HighShare * 2006:Q1 & $\begin{array}{c}0.006 * * * \\
(0.001)\end{array}$ \\
\hline Share65+*2006:Q2 & $\begin{array}{c}0.140 * * * \\
(0.028)\end{array}$ & HighShare * 2006:Q2 & $\begin{array}{c}0.007 * * * \\
(0.001)\end{array}$ \\
\hline Share65+*2006:Q3 & $\begin{array}{c}0.093 * * * \\
(0.034)\end{array}$ & HighShare * 2006:Q3 & $\begin{array}{c}0.004 * * * \\
(0.001)\end{array}$ \\
\hline Share65+*2006:Q4 & $\begin{array}{l}0.083^{* *} \\
(0.036)\end{array}$ & HighShare * 2006:Q4 & $\begin{array}{l}0.004 * * \\
(0.002)\end{array}$ \\
\hline Share65+*2007:Q1 & $\begin{array}{c}0.133 * * * \\
(0.037)\end{array}$ & HighShare* 2007:Q1 & $\begin{array}{c}0.006 * * * \\
(0.002)\end{array}$ \\
\hline Share65+*2007:Q2 & $\begin{array}{c}0.131 * * * \\
(0.037)\end{array}$ & HighShare* 2007:Q2 & $\begin{array}{c}0.005^{* * * *} \\
(0.002)\end{array}$ \\
\hline Share65+*2007:Q3 & $\begin{array}{c}0.135^{* * * *} \\
(0.034)\end{array}$ & HighShare* 2007:Q3 & $\begin{array}{c}0.005^{* * * *} \\
(0.002)\end{array}$ \\
\hline Share65+*2007:Q4 & $\begin{array}{c}0.135 * * * \\
(0.037) \\
\end{array}$ & HighShare* 2007:Q4 & $\begin{array}{c}0.005^{* * *} \\
(0.002) \\
\end{array}$ \\
\hline
\end{tabular}

Notes: $* * * \mathrm{p}<0.01, * * \mathrm{p}<0.05,{ }^{*} \mathrm{p}<0.1$. Clustered standard errors at the 3 -digit ZIP code level; all specifications include quarter fixed effects, 3-digit ZIP code fixed effects, condition fixed effects. All Instrument x quarter interactions are included in the regression, however the 2008-2010 coefficients are not presented in this table to conserve space. Includes the 50 drugs that advertised during the study period for 5 chronic conditions: depression, diabetes, hyperlipidemia, hypertension, and osteoporosis. 
Table 5 - Total Utilization of Chronic Drugs - Alternative Specifications

\begin{tabular}{|c|c|c|c|c|}
\hline \multirow{3}{*}{ Dependent Variable: \# of Prescriptions } & \multicolumn{2}{|c|}{ Reduced Form } & \multicolumn{2}{|c|}{ 2SLS } \\
\hline & $\begin{array}{c}\text { Instrument= } \\
\text { Share65+*Post }\end{array}$ & $\begin{array}{l}\text { Instrument= } \\
\text { High Elderly } \\
\text { Share*Post }\end{array}$ & $\begin{array}{c}\text { Instrument }= \\
\text { Share65+*Post }\end{array}$ & $\begin{array}{l}\text { Instrument= } \\
\text { High Elderly } \\
\text { Share*Post }\end{array}$ \\
\hline & & & & \\
\hline 1. Baseline Specification & $\begin{array}{c}(1) \\
0.107 * * * \\
(0.023)\end{array}$ & $\begin{array}{c}(2) \\
0.005 * * * \\
(\mathbf{0 . 0 0 1 )}\end{array}$ & $\begin{array}{c}(3) \\
0.017 * * * \\
(0.004)\end{array}$ & $\begin{array}{c}(4) \\
0.014 * * * \\
(0.005)\end{array}$ \\
\hline $\begin{array}{l}\text { 2. Adding zipcode-specific } \\
\text { linear trends }\end{array}$ & $\begin{array}{c}0.102 * * * \\
(0.021)\end{array}$ & $\begin{array}{c}0.005 * * * \\
(0.001)\end{array}$ & $\begin{array}{c}0.010 * * * \\
(0.003)\end{array}$ & $\begin{array}{c}0.008 * * * \\
(0.002)\end{array}$ \\
\hline 3. Excluding 2008-2010 & $\begin{array}{c}0.097 * * * \\
(0.018)\end{array}$ & $\begin{array}{c}0.004 * * * \\
(0.001)\end{array}$ & $\begin{array}{c}0.011^{* * * *} \\
(0.003)\end{array}$ & $\begin{array}{c}0.008^{* * * *} \\
(0.003)\end{array}$ \\
\hline $\begin{array}{l}\text { 4. Including only } \\
\text { continuously enrolled firms }\end{array}$ & $\begin{array}{c}0.072 * * * \\
(0.027)\end{array}$ & $\begin{array}{l}0.004 * * \\
(0.002)\end{array}$ & $\begin{array}{l}0.012^{* *} \\
(0.006) \\
\end{array}$ & $\begin{array}{l}0.015^{*} \\
(0.008) \\
\end{array}$ \\
\hline
\end{tabular}

Notes: $* * * \mathrm{p}<0.01, * * \mathrm{p}<0.05, * \mathrm{p}<0.1$. Clustered standard errors at the 3 -digit ZIP code level; all specifications include quarter fixed effects, 3-digit ZIP code fixed effects, condition fixed effects. Each cell represents the coefficient on Instrument $x$ Post from a separate regression. The specifications are as follows: 1) same as Table 3, 2) adds 3-digit ZIP code specific linear trends, 3) excludes the years 2008-2010, 4) includes only firms that were continuously in the claims sample from 2004-2010. Includes the 50 drugs that advertised during the study period for 5 chronic conditions: depression, diabetes, hyperlipidemia, hypertension, and osteoporosis. 


\section{Table 6 - Effects for Advertised Drug Classes vs. Non-Advertised Drug Classes}

\begin{tabular}{lc}
\hline \hline Dependent Variable: & \# of Prescriptions \\
\hline A. Instrument=Share65+*Post & $1.787^{* * *}$ \\
Post*Share65+*Advertise & $(0.247)$ \\
& $0.432^{* * *}$ \\
Post*Share65+ & $(0.120)$ \\
& \\
B. Instrument=High Elderly Share*Post & $0.105^{* * *}$ \\
Post*High Elderly Share*Advertise & $(0.018)$ \\
& 0.009 \\
Post*High Elderly Share & $(0.008)$ \\
& \\
Zipcode x Advertised Class x Quarter Obs & 42,938 \\
\hline
\end{tabular}

Notes: $* * * \mathrm{p}<0.01, * * \mathrm{p}<0.05,{ }^{*} \mathrm{p}<0.1$. Clustered standard errors at the 3 -digit ZIP code level; all specifications include quarter fixed effects, 3-digit ZIP code fixed effects, Advertise indicator (equals 1 when the drug class has any advertising during the study period, zero otherwise), Post x Advertise, Advertise x Share 65+ (or Advertise $\mathrm{x}$ High Elderly Share). Sample includes the top 10 advertised drugs classes and top 10 non-advertised drug classes (see Appendix Table B.3 for the full list of drug classes included). Each Zipcode x Quarter has two observations: one for mean utilization of advertised drugs, one for mean utilization of non-advertised drugs. Data is from 20042010. 


\section{Table 7 - Within-DMA Total Utilization of Chronic Drugs}

\begin{tabular}{|c|c|c|c|}
\hline \multirow[t]{2}{*}{ Dependent Variable: } & \multicolumn{3}{|c|}{ \# of Prescriptions } \\
\hline & & & DMA $x$ \\
\hline & Baseline & ZIP3 level & Qtr FE \\
\hline & (1) & (2) & (3) \\
\hline \multicolumn{4}{|l|}{ A. Instrument $=$ Share $65+*$ Post } \\
\hline Share65+*Post (DMA level) & $\begin{array}{c}0.111 * * * \\
(0.033)\end{array}$ & & \\
\hline Share65+*Post (ZIP3 level) & & $\begin{array}{c}0.087 * * * \\
(0.027)\end{array}$ & $\begin{array}{c}0.015 \\
(0.026)\end{array}$ \\
\hline \multicolumn{4}{|l|}{ B. Instrument=High Elderly Share ${ }^{*}$ Post } \\
\hline High Elderly Share*Post (DMA level) & $\begin{array}{c}0.003^{* *} \\
(0.002)\end{array}$ & & \\
\hline High Elderly Share*Post (ZIP3 level) & & $\begin{array}{c}0.006^{* * * *} \\
(0.002)\end{array}$ & $\begin{array}{c}0.002 \\
(0.002)\end{array}$ \\
\hline Mean of Dep. Var. (pre- Part D) & 0.10 & 0.10 & 0.10 \\
\hline Zipcode x Condition x Quarter Obs & 67,495 & 67,495 & 67,495 \\
\hline
\end{tabular}

Notes: $* * * \mathrm{p}<0.01, * * \mathrm{p}<0.05,{ }^{*} \mathrm{p}<0.1$. Clustered standard errors at the 3 -digit ZIP code level; all specifications include quarter fixed effects, 3-digit ZIP code fixed effects, condition fixed effects. The specifications are as follows. Column 1: same as Table 3, but for sample of ZIP codes that are uniquely matched to one DMA, elderly share is computed at the DMA-level; Column 2: elderly share is computed at 3-digit ZIP code level; Column 3: adds DMA x quarter fixed effects, elderly share is computed at 3-digit ZIP code level. Includes the 50 drugs that advertised during the study period for 5 chronic conditions: depression, diabetes, hyperlipidemia, hypertension, and osteoporosis. 


\section{Table 8 - Total Utilization of Chronic Drugs, 2SLS - Alternative Outcomes}

\begin{tabular}{|c|c|c|c|c|c|c|}
\hline \multirow[t]{2}{*}{ Dependent Variable: } & \multicolumn{2}{|c|}{ \# of Prescriptions } & \multicolumn{2}{|c|}{ D Days Supply } & \multicolumn{2}{|c|}{ Any Use } \\
\hline & Full Sample & 2004-2007 & Full Sample & $2004-2007$ & Full Sample & $2004-2007$ \\
\hline & (1) & (2) & (3) & (4) & (5) & (6) \\
\hline \multicolumn{7}{|l|}{ A. Instrument $=$ Share $65+*$ Post } \\
\hline Views per Person (Non-Elderly) & $\begin{array}{c}0.017 * * * \\
(0.004)\end{array}$ & $\begin{array}{c}0.011 * * * \\
(0.003)\end{array}$ & $\begin{array}{c}0.750 * * * \\
(0.217)\end{array}$ & $\begin{array}{c}0.560 * * * \\
(0.131)\end{array}$ & $\begin{array}{c}0.006 * * \\
(0.002)\end{array}$ & $\begin{array}{c}0.004 * * * \\
(0.001)\end{array}$ \\
\hline \multicolumn{7}{|c|}{ B. Instrument $=$ High Elderly Share $*$ Post } \\
\hline Views per Person (Non-Elderly) & $\begin{array}{c}0.014 * * * \\
(0.005)\end{array}$ & $\begin{array}{c}0.008^{* * * *} \\
(0.003)\end{array}$ & $\begin{array}{c}0.480 * * \\
(0.223)\end{array}$ & $\begin{array}{c}0.400^{* * * *} \\
(0.127)\end{array}$ & $\begin{array}{c}0.003 \\
(0.002)\end{array}$ & $\begin{array}{c}0.003^{* *} \\
(0.001)\end{array}$ \\
\hline Mean of Dep. Var (pre- Part D) & 0.11 & & 5.68 & & 0.06 & \\
\hline Zipcode x Condition x Quarter Obs & 107,345 & 61,440 & 107,345 & 61,440 & 107,345 & 61,440 \\
\hline \multirow[t]{3}{*}{ Dependent Variable: } & \multicolumn{2}{|c|}{ \# of Prescriptions } & \multicolumn{2}{|c|}{ Days Supply } & & \\
\hline & Full Sample & 2004-2007 & Full Sample & $2004-2007$ & & \\
\hline & (7) & (8) & (9) & (10) & & \\
\hline \multicolumn{7}{|l|}{ A. Instrument $=$ Share $65+*$ Post } \\
\hline Views per Person (Non-Elderly) & $\begin{array}{c}0.057 * * * \\
(0.017)\end{array}$ & $\begin{array}{c}0.035^{* * *} \\
(0.012)\end{array}$ & $\begin{array}{c}2.151 * * * \\
(0.533)\end{array}$ & $\begin{array}{c}1.428 * * * \\
(0.406)\end{array}$ & & \\
\hline \multicolumn{7}{|c|}{ B. Instrument $=$ High Elderly Share $*$ Post } \\
\hline Views per Person (Non-Elderly) & $\begin{array}{c}0.068 * * * \\
(0.026)\end{array}$ & $\begin{array}{l}0.028^{*} \\
(0.016)\end{array}$ & $\begin{array}{c}1.861 * * * \\
(0.681)\end{array}$ & $\begin{array}{c}1.366^{* * * *} \\
(0.523)\end{array}$ & & \\
\hline Mean of Dep. Var (pre- Part D) & 1.81 & & 90.87 & & & \\
\hline Zipcode x Condition x Quarter Obs & 100,427 & 58,624 & 100,427 & 58,624 & & \\
\hline
\end{tabular}

Notes: $* * * \mathrm{p}<0.01, * * \mathrm{p}<0.05, * \mathrm{p}<0.1$. Clustered standard errors at the 3 -digit ZIP code level; all specifications include quarter fixed effects, 3 -digit ZIP code fixed effects, condition fixed effects. Includes the 50 drugs that advertised during the study period for 5 chronic conditions: depression, diabetes, hyperlipidemia, hypertension, and osteoporosis. 


\section{Table 9 - Adherence of Chronic Drugs}

Panel A: Main Results

\begin{tabular}{|c|c|c|c|c|c|c|}
\hline \multirow[b]{3}{*}{ Dependent Variable: } & \multicolumn{3}{|c|}{ Reduced Form } & \multicolumn{3}{|c|}{$2 \mathrm{SLS}$} \\
\hline & Full & & & Full & & \\
\hline & Sample & 2004-2007 & 2005-2007 & Sample & 2004-2007 & $2005-2007$ \\
\hline & (1) & (2) & (3) & (4) & $(5)$ & (6) \\
\hline \multicolumn{7}{|l|}{ A. Instrument $=$ Share $65+*$ Post } \\
\hline Post*Share65+ & $\begin{array}{c}0.184^{* * * *} \\
(0.057)\end{array}$ & $\begin{array}{c}0.234 * * * \\
(0.056)\end{array}$ & $\begin{array}{c}0.404 * * * \\
(0.114)\end{array}$ & & & \\
\hline Views per Person (Non-Elderly) & & & & $\begin{array}{l}0.017 * * \\
(0.007)\end{array}$ & $\begin{array}{c}0.017 * * * \\
(0.005)\end{array}$ & $\begin{array}{c}0.033^{* * * *} \\
(0.013)\end{array}$ \\
\hline \multicolumn{7}{|l|}{ B. Instrument=High Elderly Share $*$ Post } \\
\hline High Elderly Share*Post & $\begin{array}{l}0.004^{*} \\
(0.003)\end{array}$ & $\begin{array}{c}0.008^{* * * *} \\
(0.003)\end{array}$ & $\begin{array}{c}0.012^{* * * *} \\
(0.004)\end{array}$ & & & \\
\hline Views per Person (Non-Elderly) & & & & $\begin{array}{c}0.008 \\
(0.005)\end{array}$ & $\begin{array}{c}0.011^{* * *} \\
(0.004)\end{array}$ & $\begin{array}{l}0.021^{* *} \\
(0.008)\end{array}$ \\
\hline Mean of Dep. Var (pre- Part D) & 0.61 & 0.61 & 0.56 & & & \\
\hline Zipcode $\mathrm{x}$ Condition $\mathrm{x}$ Quarter Obs & 102,477 & 59,252 & 44,519 & 102,477 & 59,252 & 44,519 \\
\hline
\end{tabular}

Panel B: Alternative Specifications - 2SLS Results

\begin{tabular}{|c|c|c|c|c|c|c|}
\hline \multirow[b]{3}{*}{ Dependent Variable: I(High Adherence) } & \multicolumn{3}{|c|}{ Instrument $=$ Share $65+*$ Post } & \multicolumn{3}{|c|}{ Instrument= High Elderly Share*Post } \\
\hline & Full & & & Full & & \\
\hline & Sample & 2004-2007 & 2005-2007 & Sample & 2004-2007 & $2005-2007$ \\
\hline \multicolumn{6}{|l|}{ A. All Individuals ages $40-60$} & (6) \\
\hline 1. Baseline Specification & $\begin{array}{l}0.017 * * \\
(0.007)\end{array}$ & $\begin{array}{c}0.017 * * * \\
(0.005)\end{array}$ & $\begin{array}{c}\mathbf{0 . 0 3 3} * * * \\
(\mathbf{0 . 0 1 3})\end{array}$ & $\begin{array}{c}0.008 \\
(0.005)\end{array}$ & $\begin{array}{c}0.011 * * * \\
(0.004)\end{array}$ & $\begin{array}{c}0.021 * * \\
(0.008)\end{array}$ \\
\hline $\begin{array}{l}\text { 2. Alternative MPR } \\
\text { (Including Discontinuation) }\end{array}$ & $\begin{array}{l}0.016^{*} \\
(0.008)\end{array}$ & $\begin{array}{l}0.021 * * * \\
(0.006)\end{array}$ & $\begin{array}{c}0.037^{* * * *} \\
(0.013)\end{array}$ & $\begin{array}{c}0.006 \\
(0.007)\end{array}$ & $\begin{array}{c}0.016 * * * \\
(0.005)\end{array}$ & $\begin{array}{c}0.026^{* * * *} \\
(0.009)\end{array}$ \\
\hline \multicolumn{7}{|c|}{ B. Excluding Individuals who Initiated Treatment after Part D } \\
\hline 3. Baseline Specification & $\begin{array}{c}0.022^{* * * *} \\
(0.006)\end{array}$ & $\begin{array}{c}0.020 * * * \\
(0.005)\end{array}$ & $\begin{array}{c}0.036^{* * * *} \\
(0.012)\end{array}$ & $\begin{array}{c}0.014 * * * \\
(0.004)\end{array}$ & $\begin{array}{c}0.013 * * * * \\
(0.004)\end{array}$ & $\begin{array}{c}0.023^{* * *} \\
(0.008)\end{array}$ \\
\hline $\begin{array}{l}\text { 4. Alternative MPR } \\
\text { (Including Discontinuation) }\end{array}$ & $\begin{array}{c}0.030^{* * * *} \\
(0.008)\end{array}$ & $\begin{array}{c}0.025 * * * \\
(0.005)\end{array}$ & $\begin{array}{c}0.041 * * * \\
(0.013)\end{array}$ & $\begin{array}{c}0.023 * * * \\
(0.006)\end{array}$ & $\begin{array}{c}0.019 * * * * \\
(0.005)\end{array}$ & $\begin{array}{c}0.031 * * * \\
(0.009)\end{array}$ \\
\hline
\end{tabular}

Notes: $* * * \mathrm{p}<0.01, * * \mathrm{p}<0.05, * \mathrm{p}<0.1$. Clustered standard errors at the 3 -digit ZIP code level; all specifications include quarter fixed effects, 3 -digit ZIP code fixed effects, condition fixed effects. The outcome variable is the proportion of individuals with MPR $>=80 \%$. In Panel B, each cell represents a separate regression with the coefficient on "views per person (non-elderly)" reported. Includes the 50 drugs that advertised during the study period and the drugs that did not advertise for 5 chronic conditions: depression, diabetes, hyperlipidemia, hypertension, and osteoporosis. 


\section{Table 10 - Spillover Effects for Non-Advertised Chronic Drugs}

\begin{tabular}{|c|c|c|c|c|c|c|}
\hline \multirow[b]{2}{*}{ Dependent Variable: } & \multicolumn{3}{|c|}{ Reduced Form } & \multicolumn{3}{|c|}{2 2SLS } \\
\hline & $\begin{array}{l}\text { Advertised } \\
\text { Drugs }\end{array}$ & $\begin{array}{l}\text { Non-Advertised } \\
\text { Drugs }\end{array}$ & Total & $\begin{array}{l}\text { Advertised } \\
\text { Drugs }\end{array}$ & $\begin{array}{l}\text { Non-Advertised } \\
\text { Drugs }\end{array}$ & Total \\
\hline & (1) & (2) & (3) & (4) & (5) & (6) \\
\hline \multicolumn{7}{|l|}{ A. Instrument=Share65+*Post } \\
\hline Post*Share65+ & $\begin{array}{c}0.107 * * * \\
(0.023)\end{array}$ & $\begin{array}{c}0.125 * * * \\
(0.028)\end{array}$ & $\begin{array}{c}0.233 * * * \\
(0.038)\end{array}$ & & & \\
\hline Views per Person (Non-Elderly) & & & & $\begin{array}{c}0.017 * * * \\
(0.004)\end{array}$ & $\begin{array}{c}0.020 * * * \\
(0.005)\end{array}$ & $\begin{array}{c}0.037 * * * \\
(0.008)\end{array}$ \\
\hline \multicolumn{7}{|l|}{ B. Instrument=High Elderly Share $*$ Post } \\
\hline High Elderly Share*Post & $\begin{array}{c}0.005^{* * * *} \\
(0.001)\end{array}$ & $\begin{array}{c}0.006 * * * * \\
(0.002)\end{array}$ & $\begin{array}{c}0.011 * * * \\
(0.002)\end{array}$ & & & \\
\hline Views per Person (Non-Elderly) & & & & $\begin{array}{c}0.014 * * * \\
(0.005)\end{array}$ & $\begin{array}{c}0.018^{* * * *} \\
(0.005)\end{array}$ & $\begin{array}{c}0.032^{* * * *} \\
(0.008)\end{array}$ \\
\hline $\begin{array}{l}\text { Mean of Dep. Var (pre- Part D) } \\
\text { Zipcode x Condition x Quarter Obs }\end{array}$ & $\begin{array}{c}0.11 \\
107,345\end{array}$ & $\begin{array}{c}0.07 \\
107,345\end{array}$ & $\begin{array}{c}0.18 \\
107,345\end{array}$ & $\begin{array}{c}0.11 \\
107,345\end{array}$ & $\begin{array}{c}0.07 \\
107,345\end{array}$ & $\begin{array}{c}0.18 \\
107,345\end{array}$ \\
\hline
\end{tabular}

Notes: $* * * \mathrm{p}<0.01, * * \mathrm{p}<0.05, * \mathrm{p}<0.1$. Clustered standard errors at the 3 -digit ZIP code level; all specifications include quarter fixed effects, 3 -digit ZIP code fixed effects, condition fixed effects. Includes the 50 drugs that advertised during the study period and the drugs that did not advertise for 5 chronic conditions: depression, diabetes, hyperlipidemia, hypertension, and osteoporosis. Data is from 2004-2010. 


\section{FOR ONLINE PUBLICATION}

\section{Appendix A}

\section{A.1 Decomposition of Extensive and Intensive Margin Effects}

The increase in total drug utilization we observe due to advertising is driven both by increased take-up of treatment (extensive margin) as well as increased use among existing drug users (intensive margin). In this section we decompose the overall effect of advertising into the extensive and intensive margins. We re-estimate the main 2SLS regression for total prescriptions shutting down the extensive margin effect (i.e. we hold the take-up rate constant at pre-Part D levels). This allows us to estimate the proportion of the total effect that is due to intensive margin changes. The remaining proportion of the total effect is then due to extensive margin changes. We estimate:

$$
\text { (A1) } \text { AnyUse } e_{m c t,<65}=\sigma_{m}+\tau_{c}+\epsilon_{m c t}
$$

Where AnyUse $e_{m c t,<65}$ is the proportion of non-elderly individuals with any use of prescription drugs for condition $c$ in market $m$ and quarter $t$. We estimate this equation for the pre-Part D period from 2004-2005. We then use the estimated parameters to predict $\widehat{A n y U} e_{m c t,<65}$ for the entire sample from 2004-2010. Since $\widehat{A n y U} s e_{m c t,<65}$ varies only by condition and market, the proportion that takes-up prescription drugs (i.e. extensive margin) is held constant over time.

Next we construct a counterfactual measure of total prescriptions purchased which holds the extensive margin constant: $\widehat{Y}_{m c t,<65}=\widehat{A n y U s} e_{m c t,<65} * Y_{m c t,<65}$, where $Y_{m c t,<65}$ is the average number of prescriptions purchased conditional on use. We use this constructed outcome variable to estimate the 2SLS model as before. The 2SLS results are presented in Columns 3 and 4 of Appendix Table B.4. The estimates using the counterfactual outcome, representing the intensive margin, are less than one-third the size of the baseline total effect (Columns 1 and 2). Using the preferred continuous instrument specification, this implies that extensive margin changes explain $71 \%$ to $73 \%$ of the total utilization effect. A straightforward back-of-theenvelope calculation using the pre-Part $\mathrm{D}$ take-up rate and estimated intensive margin effect from Table 8 produces similar estimates of the extensive margin effect. ${ }^{46}$

\footnotetext{
${ }^{46}$ Using the continuous instrument, the change in prescriptions purchased is 0.017 for one additional ad viewed. The change in prescriptions purchased along the intensive margin is predicted to be the fraction of the sample that
} 


\section{Appendix B}

\section{Appendix Figure B.1 - Annual Views per Person of Ads for Top 200 Brand Name Drugs, for Elderly 65+}

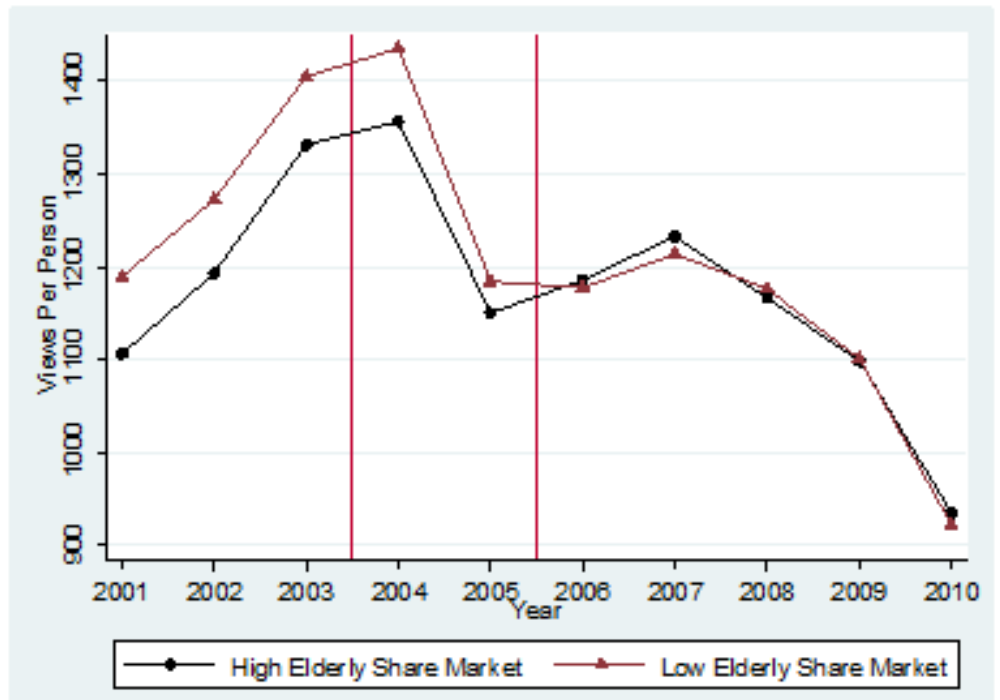

Notes: Sample means from Nielsen Ad*Views in above median elderly share markets relative to below median elderly share markets. The vertical lines represent the dates when Part D was signed into law (December 2003) and was implemented (January 2006). In Panel A, means are plotted for a balanced panel of the top 200 advertised brand-name drugs. There is a secular downward trend in overall views per person due to patent expirations of several of these drugs over this time period (in particular, four of the top 200 drugs went off patent around 2006: Pravachol, Wellbutrin XL, Zocor, and Zoloft). The downward trend in views matches the pattern in national advertising expenditures shown in Figure 1.

used chronic drugs prior to Part D (0.063) $\mathrm{x}$ the estimated change in prescriptions purchased among users $(0.057)$. Subtracting this from the total effect, we get the predicted extensive margin effect: 0.013 (or $76 \%$ of the total effect). 
Appendix Figure B.2 - Trends in Composition of Claims Data Sample
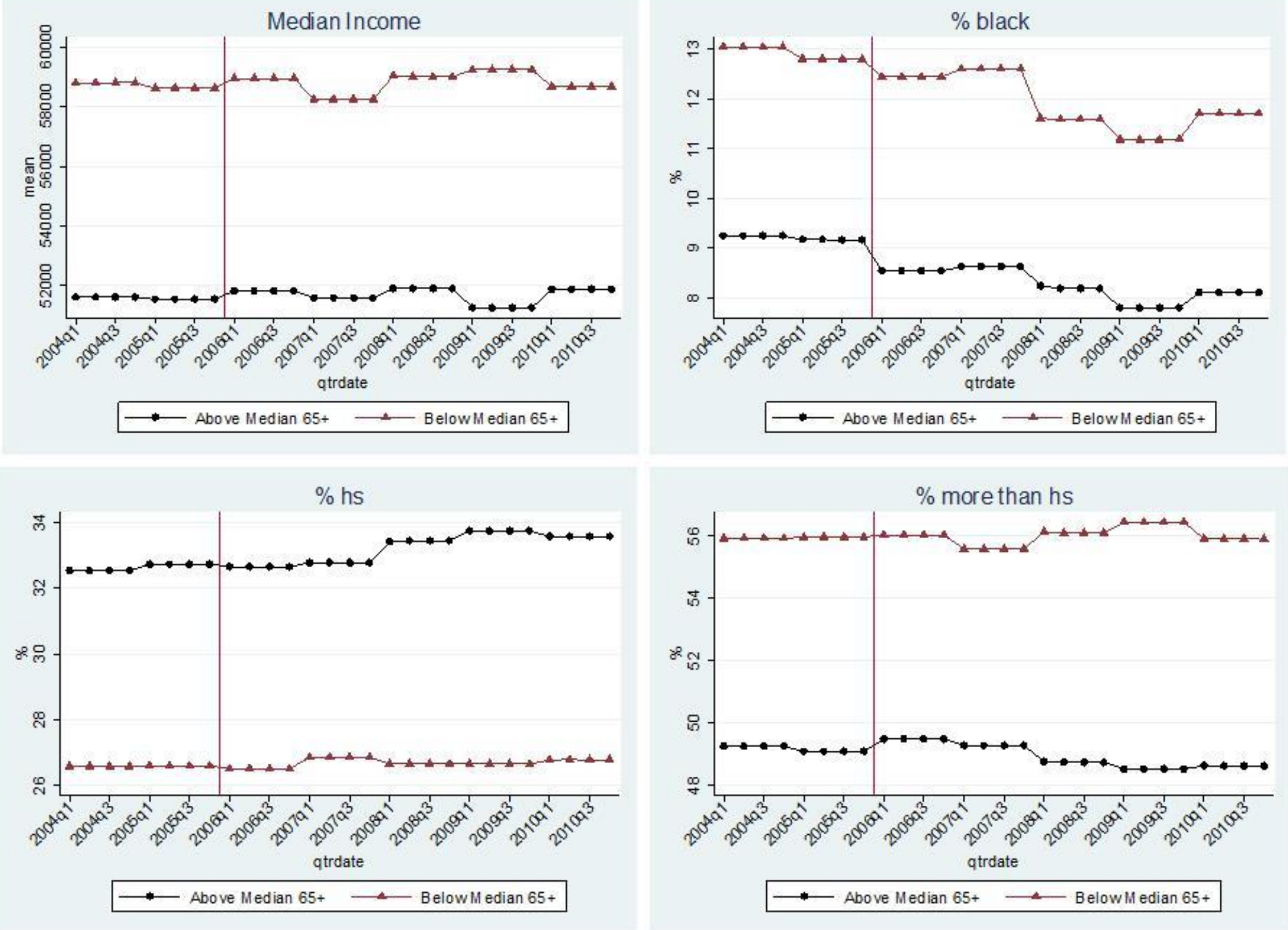

Notes: Sample means of Census 2000 characteristics linked to individuals in claims sample by 3 -digit ZIP code. 


\section{Appendix Figure B.3 - Adherence of Chronic Drugs: Medication Possession Ratio}

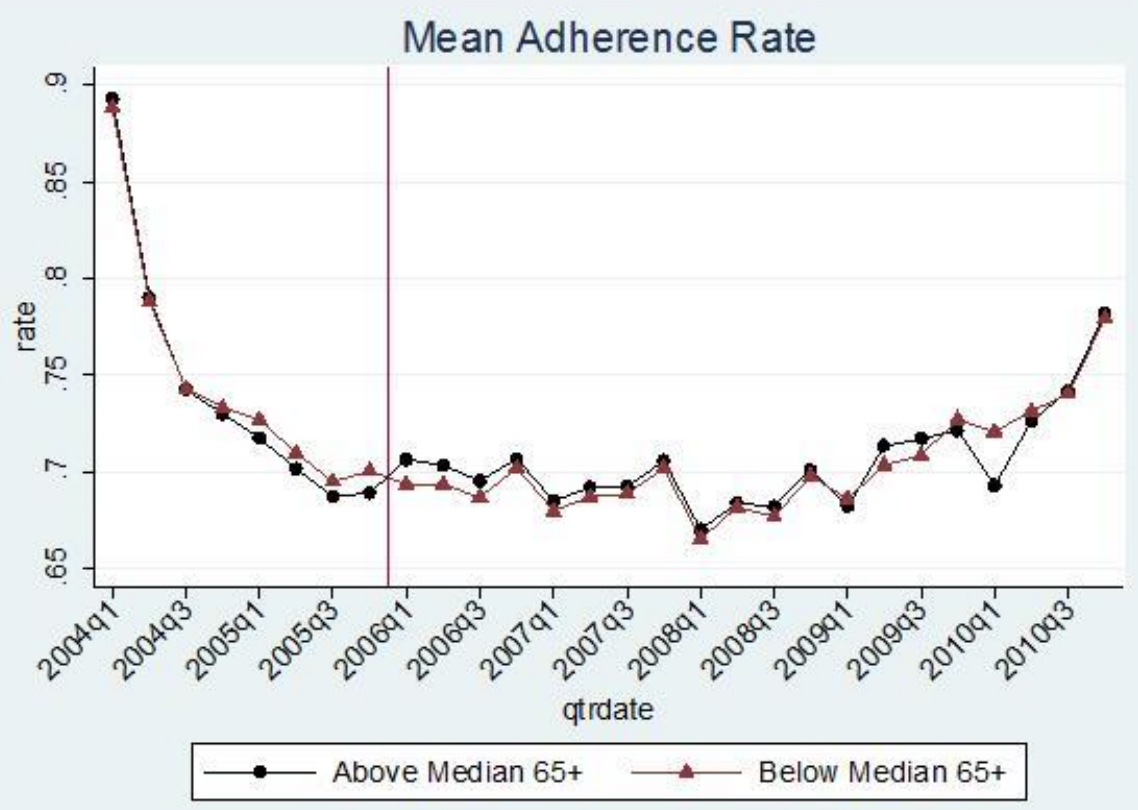

Notes: Sample means from claims (mean MPR, ages 40-60) in above median elderly share markets relative to below median elderly share markets. Includes the 50 drugs that advertised during the study period and the drugs that did not advertise for 5 chronic conditions: depressions, diabetes, hyperlipidemia, hypertension, and osteoporosis. The vertical line represents the implementation date of Medicare Part D. 
Appendix Table B.1-Top Advertised Chronic Drugs, 2001-2010

\begin{tabular}{|c|c|}
\hline Condition & Brand-Name Drug \\
\hline DEPRESSION & CYMBALTA \\
\hline DEPRESSION & EFFEXOR \\
\hline DEPRESSION & PAXIL \\
\hline DEPRESSION & PRISTIQ \\
\hline DEPRESSION & PROZAC \\
\hline DEPRESSION & SARAFEM \\
\hline DEPRESSION & WELLBUTRIN \\
\hline DEPRESSION & ZOLOFT \\
\hline DIABETES & ACTOS \\
\hline DIABETES & AVANDIA \\
\hline DIABETES & BYETTA \\
\hline DIABETES & EXUBERA \\
\hline DIABETES & HUMALOG \\
\hline DIABETES & JANUVIA \\
\hline DIABETES & LANTUS \\
\hline DIABETES & LEVEMIR \\
\hline DIABETES & METAGLIP \\
\hline DIABETES & ONGLYZA \\
\hline DIABETES & NOVOLIN \\
\hline DIABETES & NOVOLOG \\
\hline HYPERLIPIDEMIA & ALTOCOR \\
\hline HYPERLIPIDEMIA & BIDIL \\
\hline HYPERLIPIDEMIA & CADUET \\
\hline HYPERLIPIDEMIA & CRESTOR \\
\hline HYPERLIPIDEMIA & LESCOL \\
\hline HYPERLIPIDEMIA & LIPITOR \\
\hline HYPERLIPIDEMIA & LOVAZA \\
\hline HYPERLIPIDEMIA & NIASPAN \\
\hline HYPERLIPIDEMIA & PRAVACHOL \\
\hline HYPERLIPIDEMIA & TRILIPIX \\
\hline HYPERLIPIDEMIA & VYTORIN \\
\hline HYPERLIPIDEMIA & WELCHOL \\
\hline HYPERLIPIDEMIA & ZETIA \\
\hline HYPERLIPIDEMIA & ZOCOR \\
\hline HYPERTENSION & ALTACE \\
\hline HYPERTENSION & AVAPRO \\
\hline HYPERTENSION & COREG \\
\hline HYPERTENSION & DIOVAN \\
\hline HYPERTENSION & INNOPRAN \\
\hline HYPERTENSION & TEKTURNA \\
\hline HYPERTENSION & TOPROL \\
\hline OSTEOPOROSIS & ACTIVELLA \\
\hline OSTEOPOROSIS & ACTONEL \\
\hline OSTEOPOROSIS & BONIVA \\
\hline OSTEOPOROSIS & EVISTA \\
\hline OSTEOPOROSIS & FORTEO \\
\hline OSTEOPOROSIS & FOSAMAX \\
\hline OSTEOPOROSIS & PREMARIN \\
\hline OSTEOPOROSIS & PREMPRO \\
\hline OSTEOPOROSIS & RECLAST \\
\hline
\end{tabular}




\section{Appendix Table B.2 - Effect of Part D on Views Per Person for Top 200 Drugs}

\begin{tabular}{lcc}
\hline \hline Dependent Variable: Views Per Person & $\begin{array}{c}\text { Views per Person } \\
\text { (Non-Elderly) }\end{array}$ & $\begin{array}{c}\text { Views per Person } \\
\text { (Elderly) }\end{array}$ \\
\hline A. Instrument=Share65+*Post & $(1)$ & $(2)$ \\
Post*Share65+ & 64.379 & $263.830^{*}$ \\
& $(50.69)$ & $(138.34)$ \\
B. Instrument=High Elderly Share*Post & & \\
High Elderly Share*Post & $6.233^{* * *}$ & $18.055^{* * * *}$ \\
& $(1.63)$ & $(5.04)$ \\
DMA x Quarter Obs & 3,991 & 3,991 \\
\hline
\end{tabular}

Notes: $* * * \mathrm{p}<0.01, * * \mathrm{p}<0.05, * \mathrm{p}<0.1$. Clustered standard errors at the DMA level; all specifications include quarter fixed effects and DMA fixed effects. Data is from 2001-2010. 
Appendix Table B.3 - Top 10 Advertised Classes and Non-Advertised Classes

Advertised Drug Classes -- Top 10 in Terms of Utilization by Ages 40-60

ANTIHYPERLIPIDEMICS

ANTIHYPERTENSIVES

ANTIDEPRESSANTS

ANTIDIABETICS

ULCER DRUGS

BETA BLOCKERS

ANALGESICS - ANTI-INFLAMMATORY

ANTIASTHMATIC AND BRONCHODILATOR AGENTS

DERMATOLOGICALS

ANTICONVULSANTS

Non-Advertised Drug Classes -- Top 10 in Terms of Utilization by Ages 40-60

ANALGESICS - OPIOID

THYROID AGENTS

DIURETICS

ANTIANXIETY AGENTS

CALCIUM CHANNEL BLOCKERS

PENICILLINS

MACROLIDES

CORTICOSTEROIDS

FLUOROQUINOLONES

ANTI-INFECTIVE AGENTS - MISC. 


\section{Appendix Table B.4—Decomposition of Extensive and Intensive Margin Effects, 2SLS}

\begin{tabular}{|c|c|c|c|c|c|c|}
\hline \multirow[t]{3}{*}{ Dependent Variable: } & \multicolumn{2}{|c|}{ \# of Prescriptions } & \multirow{2}{*}{\multicolumn{2}{|c|}{$\begin{array}{c}\begin{array}{c}\text { Counterfactual \# of } \\
\text { Prescriptions }\end{array} \\
\text { Holding Extensive } \\
\text { Margin Constant }\end{array}$}} & \multicolumn{2}{|c|}{$\begin{array}{l}\text { \% of Total Effect is } \\
\text { Extensive Margin }\end{array}$} \\
\hline & & & & & $1-(3) /(1)$ & $1-(4) /(2)$ \\
\hline & Full Sample & $2004-2007$ & Full Sample & 2004-2007 & Full Sample & 2004-2007 \\
\hline & (1) & (2) & (3) & (4) & (5) & (6) \\
\hline \multicolumn{7}{|l|}{ A. Instrument $=$ Share 65+*Post } \\
\hline Views per Person (Non-Elderly) & $\begin{array}{c}0.017 * * * \\
(0.004)\end{array}$ & $\begin{array}{c}0.011 * * * \\
(0.003)\end{array}$ & $\begin{array}{c}0.005 * * * \\
(0.001)\end{array}$ & $\begin{array}{c}0.003^{* * * *} \\
(0.001)\end{array}$ & $71 \%$ & $73 \%$ \\
\hline \multicolumn{7}{|c|}{ B. Instrument=High Elderly Share ${ }^{*}$ Post } \\
\hline Views per Person (Non-Elderly) & $\begin{array}{l}0.014 * * * \\
(0.005)\end{array}$ & $\begin{array}{c}0.008 * * * \\
(0.003)\end{array}$ & $\begin{array}{l}0.006 * * * \\
(0.002)\end{array}$ & $\begin{array}{l}0.003^{*} \\
(0.001)\end{array}$ & $57 \%$ & $63 \%$ \\
\hline
\end{tabular}

Notes: $* * * \mathrm{p}<0.01, * * \mathrm{p}<0.05,{ }^{*} \mathrm{p}<0.1$. Clustered standard errors at the 3-digit ZIP code level; all specifications include quarter fixed effects, 3-digit ZIP code fixed effects, condition fixed effects. Columns 1 and 2 repeat the main baseline results for total number of prescriptions purchased; Columns 3 and 4 show the effect on total prescriptions purchased coming from intensive margin changes (i.e. assuming that there are no changes in the extensive margin) as described in Appendix A; Columns 5 and 6 compute the percentage of the effect on total prescriptions purchased due to extensive margin effects. Includes the 50 drugs that advertised during the study period for 5 chronic conditions: depression, diabetes, hyperlipidemia, hypertension, and osteoporosis. 


\section{Appendix Table B.5- Adherence of Chronic Drugs - Mean Medication Possession Ratio}

\begin{tabular}{|c|c|c|c|c|c|c|}
\hline \multirow[b]{3}{*}{ Medication Possession Ratio } & \multicolumn{3}{|c|}{ Reduced Form } & \multicolumn{3}{|c|}{2 2SLS } \\
\hline & Full & & & Full & & \\
\hline & Sample & 2004-2007 & $2005-2007$ & Sample & 2004-2007 & 2005-2007 \\
\hline & (1) & (2) & (3) & (4) & (5) & (6) \\
\hline \multicolumn{7}{|l|}{ A. Instrument $=$ Share $65+*$ Post } \\
\hline Post*Share65+ & $\begin{array}{c}0.195 * * * \\
(0.067)\end{array}$ & $\begin{array}{c}0.219 * * * \\
(0.073)\end{array}$ & $\begin{array}{c}0.414 * * * \\
(0.140)\end{array}$ & & & \\
\hline Views per Person (Non-Elderly) & & & & $\begin{array}{c}0.018^{* *} \\
(0.008)\end{array}$ & $\begin{array}{c}0.016^{* *} \\
(0.007)\end{array}$ & $\begin{array}{c}0.034 * * \\
(0.015)\end{array}$ \\
\hline \multicolumn{7}{|l|}{ B. Instrument $=$ High Elderly Share $*$ Post } \\
\hline High Elderly Share*Post & $\begin{array}{l}0.005^{*} \\
(0.003)\end{array}$ & $\begin{array}{c}0.007 * * \\
(0.003)\end{array}$ & $\begin{array}{c}0.012 * * * \\
(0.004)\end{array}$ & & & \\
\hline Views per Person (Non-Elderly) & & & & $\begin{array}{l}0.009^{*} \\
(0.005)\end{array}$ & $\begin{array}{c}0.009^{* *} \\
(0.004)\end{array}$ & $\begin{array}{c}0.020^{* *} \\
(0.009)\end{array}$ \\
\hline Mean of Dep. Var (pre- Part D) & 0.75 & 0.75 & 0.71 & & & \\
\hline Zipcode $\mathrm{x}$ Condition $\mathrm{x}$ Quarter Obs & 102,477 & 59,252 & 44,519 & 102,477 & 59,252 & 44,519 \\
\hline
\end{tabular}

Notes: $* * * \mathrm{p}<0.01, * * \mathrm{p}<0.05, * \mathrm{p}<0.1$. Clustered standard errors at the 3 -digit ZIP code level; all specifications include quarter fixed effects, 3-digit ZIP code fixed effects, condition fixed effects. The outcome variable is the medication possession ratio (MPR). Includes the 50 drugs that advertised during the study period and the drugs that did not advertise for 5 chronic conditions: depression, diabetes, hyperlipidemia, hypertension, and osteoporosis. 


\section{Appendix Table B.6 - Effects on Total Chronic Drug Spending}

\begin{tabular}{|c|c|c|c|c|c|c|c|}
\hline \multirow[b]{2}{*}{ Dependent Variable: } & \multirow[b]{2}{*}{ Total Expenditures } & \multicolumn{3}{|c|}{ Reduced Form } & \multicolumn{3}{|c|}{ 2SLS } \\
\hline & & $\begin{array}{l}\text { Advertised } \\
\text { Drugs }\end{array}$ & $\begin{array}{c}\text { Non- } \\
\text { Advertised } \\
\text { Drugs }\end{array}$ & Total & $\begin{array}{l}\text { Advertised } \\
\text { Drugs }\end{array}$ & $\begin{array}{c}\text { Non- } \\
\text { Advertised } \\
\text { Drugs }\end{array}$ & Total \\
\hline & & (1) & (2) & (3) & (4) & (5) & (6) \\
\hline \multicolumn{8}{|c|}{ A. Instrument $=$ Share $65+*$ Post } \\
\hline Post*Share65+ & & $\begin{array}{c}12.488 * * * \\
(3.399)\end{array}$ & $\begin{array}{c}5.878 * * * \\
(2.033)\end{array}$ & $\begin{array}{c}18.367 * * * \\
(3.801)\end{array}$ & & & \\
\hline Views per Person (Non- & Elderly) & & & & $\begin{array}{c}1.964 * * * \\
(0.537)\end{array}$ & $\begin{array}{c}0.925 * * \\
(0.424)\end{array}$ & $\begin{array}{c}2.889 * * * \\
(0.779)\end{array}$ \\
\hline \multicolumn{8}{|c|}{ B. Instrument=High Elderly Share*Post } \\
\hline High Elderly Share*Post & & $\begin{array}{c}0.532 * * * \\
(0.205)\end{array}$ & $\begin{array}{c}0.092 \\
(0.121)\end{array}$ & $\begin{array}{l}0.624^{* *} \\
(0.248)\end{array}$ & & & \\
\hline Views per Person (Non- & Elderly) & & & & $\begin{array}{c}1.526^{* * * *} \\
(0.576)\end{array}$ & $\begin{array}{c}0.265 \\
(0.350)\end{array}$ & $\begin{array}{l}1.790 * * \\
(0.716)\end{array}$ \\
\hline Mean of Dep. Var (pre- & Part D) & 14.61 & 4.75 & 19.36 & & & \\
\hline Zipcode $\mathrm{x}$ Condition $\mathrm{x} \mathrm{Q}$ & larter Obs & 107,345 & 107,345 & 107,345 & 107,345 & 107,345 & 107,345 \\
\hline
\end{tabular}

Notes: $* * * \mathrm{p}<0.01, * * \mathrm{p}<0.05, * \mathrm{p}<0.1$. Clustered standard errors at the 3 -digit ZIP code level; all specifications include quarter fixed effects, 3-digit ZIP code fixed effects, condition fixed effects. Includes the 50 drugs that advertised during the study period and the drugs that did not advertise for 5 chronic conditions: depression, diabetes, hyperlipidemia, hypertension, and osteoporosis. Data is from 2004-2010. 